This is a repository copy of "Event-based MPC for defocusing and power production of a parabolic trough plant under power limitation" in the Depósito de Investigación de la Universidad de Sevilla

Version: Author Accepted Version

Citation: A.J. Sánchez, A.J. Gallego, J.M. Escaño \& E.F. Camacho. "Event-based MPC for defocusing and power production of a parabolic trough plant under power limitation". Solar Energy - ISSN 0038-092X. Vol.: 174, pp. 570-581. Noviembre 2018. 10.1016/i.solener.2018.09.044

To cite this publication, please use the final published version (if applicable). Please check the document version above.

Copyright: Other than for strictly personal use, it is not permitted to download, forward or distribute the text or part of it, without the consent of the author(s) and/or copyright holder(s), unless the work is under an open content license such as Creative Commons.

Takedown policy: Please contact us (idus@us.es) and provide details if you believe this document breaches copyrights. We will remove access to the work immediately and investigate your claim 


\title{
Event-Based MPC for defocusing and power production of a parabolic trough plant under power limitation
}

\author{
A.J. Sánchez ${ }^{\mathrm{a}, *}$, A.J. Gallego ${ }^{\mathrm{a}}$, J.M. Escaño ${ }^{\mathrm{b}}$, E.F. Camacho ${ }^{\mathrm{a}}$ \\ ${ }^{a}$ Departamento de Ingeniería de Sistemas y Automática, Universidad de Sevilla, Camino de los Descubrimientos s/n, 41092 Sevilla, Spain \\ ${ }^{b}$ Departamento de Ingeniería, Universidad Loyola Andalucía, Energía Solar 1. Edificio E, Campus Palmas Altas, 41014 Sevilla, Spain
}

\begin{abstract}
Optimal operation of a solar plant is generally understood as a tracking of the optimal working temperatures which maximize the net electric power. However, a commercial solar plant may receive a limitation from the Transmission System Operator due to saturation of the electrical grid. In these situations the plant moves to an operation mode in which the objective is not maximum production but compliance with the orders of the Transmission System Operator.

The paper proposes an Event-Based Gain Scheduling Generalized Predictive Control strategy for electric power production reference tracking when power limitations are imposed by the Transmission System Operator. Gain Scheduling Generalized Predictive Controllers are proposed to control fourth and third collector defocus in order to prevent heating fluid temperature from exceeding the limits of the manufacturer and therefore, avoid oil degradation. A $50 M W$ parabolic solar trough plant model has been used to design and validate the strategy. Simulation results are presented showing the advantages of using the proposed strategy.
\end{abstract}

Keywords: Solar parabolic, Model Predictive Control, Collector defocus, Electric power limitation

\section{Introduction}

During the second half of the 70s interest in renewable energies experienced a boost. This happened after the first oil crisis driven by economical factors when oil prices soared. After oil prices decreased, interest in renewable energies also decreased. Due to global warming and with the objective of reducing harmful emissions from conventional fossil power plants, interest in renewable energies has, once again, resurged (Goswami et al., 2000; Blanco and Santigosa, 2017). Currently, the renewable energies with the greatest impact on society are solar, wind and hydraulic, solar energy being the most abundant renewable energy by far.

This paper deals with the operation of parabolic solar plants. A parabolic solar plant consists of a field of parabolic-cylinder collectors arranged in loops with a cold oil inlet and hot oil outlet. The collectors focus direct solar radiation on a receiver tube through which oil circulates to heat it and send it to a heat exchanger. The next step is the steam cycle or power cycle where a steam turbine will produce electric energy.

Several Concentrating Solar Power (CSP) plants with Parabolic Trough Collectors (PTC) have been built around the world in the last decade. Examples of commercial

\footnotetext{
*Corresponding author Tel.: +34 600064314

Email addresses: asanchezdelpozo@us.es (A.J. Sánchez), gallegolen@hotmail.com (A.J. Gallego), jmesca@ieee.org (J.M. Escaño), efcamacho@us.es (E.F. Camacho)
}

CSPs currently producing are: $50 \mathrm{MW}$ Andasol solar plants (Solar Millennium AG, 2018), Helios 1/2, $50 \mathrm{MW}$ CSPs (220 hectares, 90 loops) (Helios 1, 2018), Khi Solar One in South Africa (operational since 2016) (Khi Solar One, 2018) and Solana CSP (Arizona, USA) with a gross turbine capacity of $280 M W$ (777 hectares, 808 loops) (Solana Generating Station, 2018). One of the advantages of CSP plants is the possibility of using thermal energy storage (Camacho et al., 2011; Alva et al., 2017; Sarbu and Sebarchievici, 2018). Generally, this is done by using molten salt tanks (hot and cold) (Solana Generating Station, 2018; Kaxu Solar One, 2018).

Generally, the main objective of the control systems in solar trough plants is to maintain the outlet temperature of the field around a desired set-point. Unlike conventional fossil fuel plants where the main source of energy (fuel) can be manipulated, in solar plants the main source of energy is considered a disturbance since the plant controller will have to deal with radiation transients due to clouds. In addition to clouds the daily beam radiation profile cycle is another source concern, as it affects the available solar energy. Research to improve performance in order to optimize solar power plants from the control point of view has been addressed in many ways. In most of the research works, the design of controllers is based on the ACUREX model, a parabolic trough field plant for research and experimental purposes, located in Almería, Spain (Camacho et al., 2012; Beschi et al., 2014; Lemos et al., 2014; Khoukhi et al., 2015; Alsharkawi and Rossiter, 2017).

As stated above, most of the works focus on new opti- 
mized control methods for temperature set-point tracking, constraint compliance, state estimation, just to name out a few. One of the most widespread applied techniques is Model Predictive Control (MPC). MPC techniques applied to solar plants have shown to be effective, as in Limón et al. (2008) where a Robust control of ACUREX is proposed using MPC for tracking. A Neural Network based MPC is presented in Gil et al. (2014). In Alsharkawi and Rossiter (2016), authors developed a linear time-variant state space estimation to design a Dual mode MPC. A different MPC approach is developed in Lima et al. (2016) in which the authors designed a Filtered Dynamic Matrix Control (FDMC). Authors used a filter for the prediction error so that the robustness of the control strategy is ensured. However, these works are focused on the tracking of a temperature set-point, rejection of disturbances, robustness, estimation and stability, just to name out a few.

Some of the most important topics in solar plants are costs reduction and the optimization of the plant operation (N.A Engineering, 2008; Blanco and Miller, 2017). Some examples can be found in Montes et al. (2009) where a standard methodology for the economic optimization of the solar multiple in parabolic trough plants is presented. Wittmann et al. (2011) presented a methodology on how to set up an economically optimized bidding strategy at the energy exchange. The objective was to achieve maximum benefit from the production and selling price point of view. In Camacho and Gallego (2013) an optimization of the temperature operating point for solar plants is presented. The optimal temperature set-point is obtained throughout the day depending on the environmental conditions. An optimal turbine inlet pressure of a CSP plant is calculated in Desai and Bandyopadhyay (2015). This works states that the optimal turbine inlet pressure is a weak function of design radiation. However, the optimum value increases with plant size and various modifications of Rankine cycle. In Sánchez et al. (2018), the authors proposed an online non-linear model based optimization to control the inlet valves. The objective is to homogenize the solar field to avoid the loss of electric production due to dirt (different loop efficiencies).

However, there are situations in which the plant has to move into an operation mode in which the optimization of the produced power does not make sense. A commercial solar plant may receive commands of power limitation from the Transmission System Operator (TSO). Typically, when the electrical grid is saturated. In these cases, the plant is forced to decrease its electric production and maintain the power set-point determined by the TSO. Therefore, maximum power production no longer makes sense. In this situations the objective is double: fulfilling the TSO power set-point and temperature tracking. The nominal operating point of a commercial plant is generally around the $393{ }^{\circ} \mathrm{C}$ field outlet temperature (Ibersol 1, 2018; Solaben 2, 2018). The plant will have a time period to reduce its generated electric power to the setpoint determined by the TSO. If the plant does not com- ply with the determined set-point it would face economic sanctions. To decrease power it is necessary to decrease the oil flow-rate that reaches the heat exchanger where the steam phase begins. Plants with Thermal Energy Storage (TES) are able to deal with this situation, at least for a while, by diverting part of the flow-rate to the TES until these are saturated. Plants that do not have TES cannot cope with this so easily. This work focuses on plants that do not have TES such as Ibersol 1 (2018), Solaben 2 (2018), Guzmán (2018), Helios 1 (2018). Decreasing the flow-rate increases the outlet temperature. However, if the flow-rate is used to control the power, a new mechanism is necessary to control the field outlet temperature at the nominal operating point. This mechanism is the defocusing of collectors. This is done by augmenting the incidence angle between the solar beam and the normal to the mirror plane and thus the efficiency decreases. Typically, this control is only used in commercial plants to prevent the oil temperature from exceeding a maximum from which the oil begins to degrade. The main motivation of this paper is dealing with the operation of a parabolic trough plant under power limitation.

In this work, a novel Event based Gain Scheduling Generalized Predictive Control (EGS-GPC) for electric power reference tracking when a power limitation appears is proposed. A new control strategy for defocusing the fourth and third collectors of each loop is developed in order to control the outlet temperature and to avoid loop temperature from exceeding the limit temperature, since the flow-rate control will be devoted to electric power reference tracking. To design the control strategy a $50 \mathrm{MW}$ parabolic trough plant model will be used instead of the ACUREX model.

This paper is organized as follows: In section 2 the 50 $M W$ solar plant model and the mathematical models that have been used are described. In section 3, a flow-rate Gain Scheduling Generalized Predictive Control scheme (GS-GPC) is explained as well as a series Feed-Forward (FF). In section 4, the fourth collector defocus EGS-GPC is developed. In section 5, power EGS-GPC is detailed as well as a GS-GPC for the third collector. Simulation results are presented in section 6 . Finally, in section 7 , the paper draws to a close with some concluding remarks and future work.

\section{Parabolic trough field model}

Research works have used the ACUREX solar plant model for design and testing. The ACUREX field, located at the Plataforma Solar de Almería, consists of 480 parabolic trough collectors. The collectors are arranged in 10 loops, each one composed of two rows of 12 modules. The total length of each loop is $172 \mathrm{~m}$, which comprises active parts $(142 \mathrm{~m})$ and passive parts, i.e. joints and other parts not reached by concentrated radiation $(30 \mathrm{~m})$.

However, to design, simulate and present the results of the proposed strategy in this paper, it seems reasonable 


\section{Nomenclature}

A Cross-sectional area of the pipe $\left(m^{2}\right)$

C

$D$

G

$H_{l}$

$H_{t}$

I

$k$

$K_{\text {opt }}$

$L$

$n_{o}$

$N u$

$P$

$P_{c p}$

phi

$\operatorname{Pr}$

$P W_{\text {ref }}$

$P W_{\text {set-point }}$

$P W_{T S O}$

$Q$

$q_{f f}$

$Q_{f f}$

$Q_{\text {high }}$

$Q_{\text {low }}$

$Q_{P W}$

$R e$

S

Specific heat capacity $J /\left(k g^{\circ} K\right)$

Hydraulic diameter of the pipe $(m)$

Collector aperture $(m)$

Global coefficient of thermal loss

$\left(W /\left(m^{2 \circ} K\right)\right)$

Coefficient of heat transmission metal-fluid

$\left(W /\left(m^{2 \circ} K\right)\right)$

Solar radiation $\left(W / m^{2}\right)$

Thermal conductivity $(W /(m \cdot K))$

Optical efficiency

Length of pipeline $(m)$

Geometric efficiency

Nusselt number

Power $(M W)$

Fixed factor (loop geometrical and thermal properties)

Fixed factor

Prandtl number

Reference to the Power GS-GPC

Power set-point by TSO

Boolean variable indicating the plant is on limitation mode

Oil flow rate $\left(\mathrm{m}^{3} / \mathrm{s}, \mathrm{m}^{3} / \mathrm{h}, \mathrm{kg} / \mathrm{s}\right)$

Computed flow-rate for one loop

Computed flow-rate for the complete field

Flow limit to consider the plant is saturated

Flow limit to consider the plant is not

saturated

Flow-rate computed by the Power GS-GPC

Reynolds number

Total reflective surface $\left(m^{2}\right)$
$T_{a}$

$T_{C 3}^{i}$

$T_{\text {in }}$

$T_{\text {out }}$

$T_{\text {mean }}$

$T_{\text {low }}$

$T_{\text {high }}$

$T_{\text {ref }}$

$T_{r e f-C 3}$

$T_{\text {ref-C4 }}$

$T_{\text {ref-sat }}$

$T_{\text {ref-nosat }}$

$T S O_{L}$

$x$

$\Delta T$

$\beta_{k}^{i}$

$\beta_{k-1}^{i}$

$\gamma_{k}^{i}$

$\gamma_{k-1}^{i}$

$\mu$

$\nu$

$\rho$

$\mu_{\text {rankine }}$

$\mu_{\text {exchanger }}$

$\mu_{\text {parasitics }}$
Time $(s)$

Temperature $\left({ }^{\circ} C, K\right)$

Ambient temperature

Third collector temperature, loop $i$

Inlet temperature

Outlet temperature

Mean temperature between inlet and outlet temperature

Field outlet temperature to consider the plant is not saturated

Field outlet temperature to consider the plant is saturated

Temperature reference provided by the GS-GPC controller to the FeedForward Temperature set-point applied to the $3^{r d}$ collector

Temperature set-point applied to the $4^{\text {th }}$ collector

Temperature set-point for the $4^{\text {th }}$ collector in saturation

Temperature set-point for the $4^{\text {th }}$ collector not in saturation

Boolean variable indicating a power limitation arrived

Space $(m)$

the thermal difference $\left({ }^{\circ} \mathrm{C}\right)$

Defocus angle, $4^{\text {th }}$ collector, loop $i$, instant $k$ (deg)

Defocus angle, $4^{\text {th }}$ collector, loop $i$, instant $k-1$

Defocus angle, $3^{\text {th }}$ collector, loop $i$, instant $k$

Defocus angle, $3^{\text {th }}$ collector, loop $i$, instant $k-1$

Dynamic viscosity of the fluid $(P a \cdot s=N \cdot s / m 2=k g /(m \cdot s))$

Kinematic viscosity $\left(\mathrm{m}^{2} / \mathrm{s}\right)$

Density $\left(\mathrm{kg} / \mathrm{m}^{3}\right)$

Rankine cycle efficiency

Heat exchanger efficiency

Parasitic effects efficiency 
to use a plant model of approximate dimensions and electric production as existing commercial plants. The chosen plant model is a $50 \mathrm{MW}$ of electric production without TES (Helios 1, 2018; Guzmán, 2018; Ibersol 1, 2018). Plants that have thermal storage may, for a time, deal with power limitations by diverting part of the flow-rate to the TES. Plants that do not have thermal storage cannot divert flow-rate at any time.

In this paper, two types of mathematical models are proposed for the plant: a concentrated parameter model will be used in the FF module of the control strategy, and a distributed parameter model will be used for simulation purposes. Both models have been obtained through tests and validations conducted at the plant and have been used by many authors. For a complete description of the plant and the modeling procedure, refer to Carmona (1985), Camacho et al. (1997).

\subsection{Parabolic trough field}

The solar field of a $50 \mathrm{MW}$ plant is, unlike the ACUREX field, extensive. The total length of each loop in ACUREX, as previously mentioned, is $172 \mathrm{~m}$, whereas in a $50 \mathrm{MW}$ commercial plant the length is around $600 \mathrm{~m}$ with 4 collectors each loop (Extresol 1, 2018; Solaben 2, 2018; Guzmán, 2018). The number of loops is another important factor. In commercial plants, the number of loops is $80-100$ loops (Ibersol 1, 2018; Helios 1, 2018; Solaben 2, 2018; Guzmán, 2018; Majadas I, 2018; Palma del Río I, 2018).

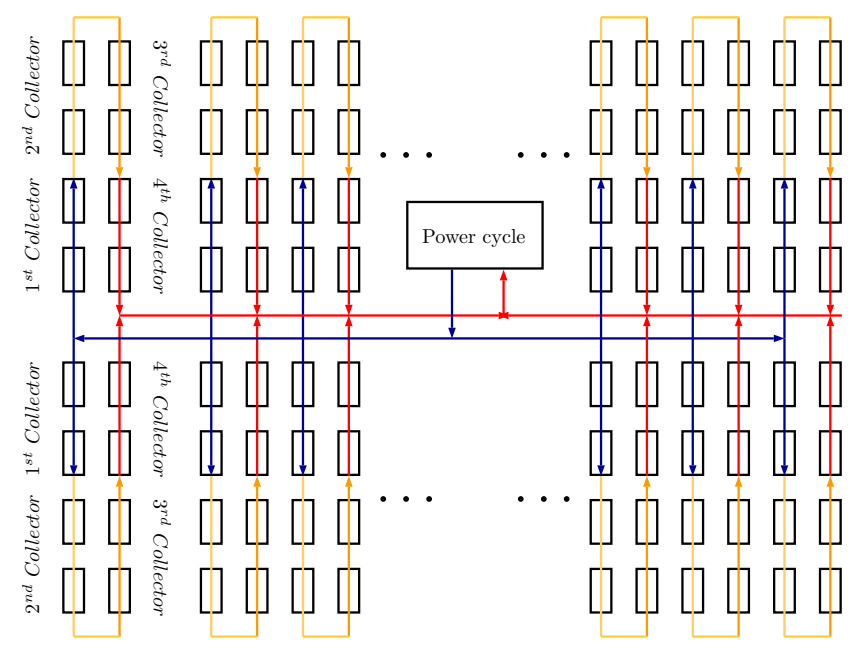

Figure 1 Parabolic trough plant general schematic

The position of the field of a commercial solar plant, for efficiency reasons, is north-south, unlike ACUREX, which is east-west. The plant model that will be used for the rest of the paper consists of 90600 meter loops where each collector is $150 \mathrm{~m}$ long. In Fig. 1 a schematic parabolic trough plant is shown.

\subsection{Collectors, receiver tube and heat transfer fluid}

For the simulation model of this paper the collector EuroTrough ET150 (Rohani et al., 2017; Andasol 1, 2018;
System Advisor Model (SAM). NREL, 2018) is selected. In order to simulate the field, it is necessary to describe the collector in terms of parameters. In Table 1 the main parameters of the EuroTrough ET150 collector are shown (Geyer et al., 2002; Kearney, 2007; System Advisor Model (SAM). NREL, 2018).

Table 1

EuroTrough ET150 parameters.

\begin{tabular}{lll}
\hline Description & Value & Unit \\
\hline Focal length & 1.71 & $m$ \\
Aperture width & 5.77 & $m$ \\
Aperture area & 817.5 & $m^{2}$ \\
Number of Modules per Drive & 12 & Unitless \\
Length per Solar Collector Assembly (SCA) & 148.5 & $m$ \\
SCAs per loop & 4 & Unitless \\
Heat Collection Element (HCE) Type & Evacuated tube & Unitless \\
\hline
\end{tabular}

The receiver tube used in the model is the Schott PTR 70 since it is one of the most used in commercial plants (Extresol 1, 2018; Ibersol 1, 2018; Andasol 1, 2018). The reader should refer to SCHOTT Solar CSP GmbH (2018) for a complete description of Schott PTR70.

The Heat Transfer Fluid (HTF) is used to generate the necessary steam for the steam power cycle. Therminol Vp1 and DOWTHERM $M^{T M}$ HTFs are the most used fluids in commercial solar plants. In this paper, Therminol $V p 1$ is used. It is a synthetic thermal oil with a Biphenyl oxide/Diphenyl composition. This HTF can operate at temperatures between $12{ }^{\circ} \mathrm{C}$ and $400{ }^{\circ} \mathrm{C}$ (Therminol VP1 HTF, 2018). Above $400{ }^{\circ} \mathrm{C}$ the fluid degrades. Fluid density $\left(\rho_{f}\right)$ and specific heat capacity $\left(C_{f}\right)$ are temperature dependent and can be obtained through equations (1) and (2). The reader should refer to the manufacturer, Therminol VP1 HTF (2018), for more parameters approximations.

$$
\begin{array}{r}
\rho_{f}=-0.90797 \cdot T+0.00078116 \cdot T^{2}-2.367 \times 10^{-6} \cdot T^{3} \\
+1083.25
\end{array}
$$

The last approximation is the maximum amount of HTF needed to generate $50 M W$. This calculation is performed under nominal operating conditions, at a field outlet temperature of $393{ }^{\circ} \mathrm{C}$. To calculate the maximum flowrate to produce $50 M W$, equation (3) is used. The power generation is proportional to the oil flow-rate and the temperature difference that occurs in the heat exchanger. This difference is around $90-100{ }^{\circ} \mathrm{C}$ approximately in current plants, so the field inlet temperature is $293{ }^{\circ} \mathrm{C}$ approximately at nominal operation.

$$
Q=\frac{P \cdot 10^{6}}{\Delta T \cdot C_{f} \cdot \mu_{\text {rankine }} \cdot \mu_{\text {exchanger }} \cdot \mu_{\text {parasitics }}}
$$


The efficiency of the Rankine cycle in current $50 \mathrm{MW}$ solar plants goes up to $38.1 \%$ (Andasol 1, 2018; Extresol 1, 2018). Parasitic effects and heat exchanger efficiencies reduce the generated power and therefore there is a gross and a net power (System Advisor Model (SAM). NREL, 2018). Table 2 shows the selected values for these efficiencies. To generate approximately $50 \mathrm{MW}$, the maximum flow-rate calculated for the simulation model is $655 \mathrm{~kg} / \mathrm{s}$ $\left(3350 \mathrm{~m}^{3} / \mathrm{h}\right)$ approximately at $393{ }^{\circ} \mathrm{C}$.

Table 2 Flow-rate parameter values.

\begin{tabular}{lcccc}
\hline Parameter & $\Delta T$ & $\mu_{\text {rankine }}$ & $\mu_{\text {exchanger }}$ & $\mu_{\text {parasitics }}$ \\
\hline Value & $95^{\circ} \mathrm{C}$ & $38.1 \%$ & $90 \%$ & $90 \%$ \\
\hline
\end{tabular}

\subsection{Distributed parameter model}

The dynamics of the distributed solar collector field are described by the following system of partial differential equations (PDE) describing the energy balance (Carmona, 1985; Camacho et al., 1997):

$\rho_{m} C_{m} A_{m} \frac{\partial T_{m}}{\partial t}=I K_{o p t} n_{o} G-H_{l} G\left(T_{m}-T_{a}\right)-L H_{t}\left(T_{m}-T_{f}\right)$

$\rho_{f} C_{f} A_{f} \frac{\partial T_{f}}{\partial t}+\rho_{f} C_{f} Q \frac{\partial T_{f}}{\partial x}=L H_{t}\left(T_{m}-T_{f}\right)$

where the subindex $m$ refers to the metal and $f$ refers to the fluid. The geometric efficiency depends on hourly angle, solar hour, declination, day of the year, local latitude and collector dimensions. The density $\rho$, specific heat $C$ and coefficients $H_{t}$ and $H_{l}$ depend on fluid temperature. The coefficient of heat transmission depends on temperature and oil flow (Camacho et al., 1997). $H_{l}$ can be obtained from Burkholder et al. (2007), Lüpfert et al. (2008) while $H_{t}$ can be calculated with the equations (5) for a turbulent flow-rate inside a pipeline where $p h i$ is a fixed factor and $Q$ is the flow-rate in $\mathrm{m}^{3} / \mathrm{s}$.

$$
\begin{aligned}
& \operatorname{Re}=Q \cdot D /(\nu \cdot A) \\
& \operatorname{Pr}=C_{f} \cdot \mu / k \\
& p h i=1.023 \\
& N u=0.025 \cdot\left(\operatorname{Re}^{0.79}\right) \cdot\left(\operatorname{Pr}^{0.42}\right) \cdot p h i \\
& H_{t}=N u \cdot k / D
\end{aligned}
$$

The model is discretized in the longitudinal dimension of the tube so the dynamics of each loop can be simulated as a chain of sub-models. A segment length of 1.98 meter has been chosen for the implementation of the simulation model (300 segments per loop). For the ACUREX plant, the chosen number of segments is typically 172 with a 1 meter length segment. This amount of segments provides good performance for the simulation of the field by using the distributed parameters model. However, ACUREX loop length is 172 meter while in this case a 600 meter loop length is considered for the $50 \mathrm{MW}$ plant simulation. A simulation with 300 segments of approximately 2 meters length each also provides good simulation performance and reduces the computation time. Number of segments can always be increased but with a higher computational cost. Reducing too much the number of segments will entail a loss in the nonlinear dynamic resolution of the field simulation.

\subsection{Concentrated parameter model}

The concentrated parameter model provides a general description of the whole field. The variation in the internal energy of the fluid can be described by the equation:

$C \frac{d T_{\text {out }}}{d t}=K_{\text {opt }} n_{o} S I-Q P_{c p}\left(T_{\text {out }}-T_{\text {in }}\right)-H_{l}\left(T_{\text {mean }}-T_{a}\right)$

This model will be used to implement a series FeedForward controller.

\section{Flow-Rate Model Predictive Control Scheme}

This section describes the control scheme used to perform the outlet temperature tracking. A GS-GPC is used for the flow-rate control scheme and a series FF is used for disturbance rejection. The series FF has proved to be very effective at rejecting measurable disturbances affecting the solar field. (Camacho et al., 1997).

\subsection{Generalized Predictive Control}

The GPC algorithm is based on the following singleinput single-output model (Camacho and Bordons, 2007):

$$
A\left(z^{-1}\right) y_{k}=z^{-d} B\left(z^{-1}\right) u_{k-1}+\frac{C\left(z^{-1}\right)}{\Delta} e_{k}
$$

where $u_{k}$ and $y_{k}$ are the control and output sequences of the plant, $e_{k}$ is a zero mean white noise term and $\Delta$ is the integrator operator. $A, B$ and $C$ are polynomials in the backward shift operator $z^{-1}$ :

$$
\begin{aligned}
& A\left(z^{-1}\right)=1+a_{1} z^{-1}+\ldots+a_{n a} z^{-n a} \\
& B\left(z^{-1}\right)=b_{0}+b_{1} z^{-1}+\ldots+b_{n b} z^{-n b} \\
& C\left(z^{-1}\right)=1+c_{1} z^{-1}+\ldots+c_{n c} z^{-n c}
\end{aligned}
$$

where $d$ is the dead time of the system and $\Delta$ is the operator $1-z^{-1}$. This model is known as a Controller AutoRegressive Integrated Moving-Average (CARIMA) model. Consider a multistage cost function of the form:

$$
\begin{array}{r}
J\left(N_{1}, N_{2}, N_{u}\right)=\sum_{j=N_{1}}^{N_{2}} \delta(j)[\hat{y}(k+j \mid k)-w(k+j)]^{2} \\
+\sum_{j=1}^{N_{u}} \lambda(j)[\Delta u(k+j-1)]^{2}
\end{array}
$$


where $\hat{y}(k+j \mid k)$ is an optimum $\mathrm{j}$ step ahead prediction of the system output, $N_{1}$ and $N_{2}$ are the minimum and maximum costing horizons, $N_{u}$ is the control horizon, $\delta(j)$ and $\lambda(j)$ are weighting sequences and $w(k+j)$ is the future reference trajectory. The aim of GPC is to minimise $J\left(N_{1}, N_{2}, N_{u}\right)$ in order to compute a future sequence of control actions $u(k), u(k+1), \ldots$ that drives the future plant output $y(k+j)$ close towards $w(k+j)$.

Hence given a CARIMA plant model and suitable cost function, the minimum of the cost function can be obtained by setting the gradient of $\mathbf{J}$ equal to zero and solving the control sequence $\Delta \mathbf{u}$ by the following equation (Camacho and Bordons, 2007):

$$
\Delta \mathbf{u}=\left(\mathbf{G G}^{T}+\lambda \mathbf{I}\right)^{-1} \mathbf{G}^{T}(\mathbf{w}-\mathbf{f})
$$

where matrix $\mathbf{G}$ contains the step response coefficients of the forced response model (Camacho et al., 2012), I is the eye matrix, $\mathbf{f}$ is the free response of the plant, $\mathbf{w}$ is the future reference trajectory vector and $\lambda$ is the control weighting vector (Camacho and Bordons, 2007).

\subsection{Gain Scheduling}

The design of the GS-GPC is described in Camacho et al. (1994, 1997). GS-GPC controller has demonstrated to have a very good behaviour not only in respect to setpoint tracking but also in disturbance rejection capabilities (Camacho et al., 1997). Depending on the point at which the system operates, the GS-GPC feedback gain is adjusted in order to compensate variation in the plant response under different working conditions. In a solar trough plant, the dynamic is mainly dictated by the oil flow. Four oil flow levels covering the operation range of the plant are used $\left(1494,1908,2322\right.$ and $2736 \mathrm{~m}^{3} / \mathrm{h}$ ). Since the linear models correspond to the FF plus the plant model, the input is the temperature reference from GS-GPC (input to FF) and the output is the outlet oil temperature (output of the plant) $\left({ }^{\circ} \mathrm{C}\right)$.

A suitable identification of the model parameters at four different set-points for the oil flow (1494, 1908, 2322 and $2736 \mathrm{~m}^{3} / \mathrm{h}$ ) will be used. Step responses are shown in Fig. 2. The GS-GPC has been designed assuming that the parameters of all loops are the same. It is also assumed that the field is balanced, therefore the flow going into each of the loops is the same. A global dynamic model based only on one loop is used to design the GS-GPC.

\subsection{Feed-Forward Control}

The use of a series Feed-Forward controller action has proved to be very effective at rejecting solar radiation disturbances when using linear controllers. Moreover, it significantly contributes to preserving the validity of the assumed linear description of the plant over its operation range. The FF input signal is a temperature set-point from GS-GPC control, while the control output is the oil flow-rate $q_{f f}$ which is computed by the lumped parameter description (Camacho et al., 1992):

$$
q_{f f}=\frac{K_{o p t} n_{o} S I-S H_{l}\left(T_{\text {mean }}-T_{a}\right)}{P_{c p}\left(T_{\text {ref }}-T_{i n}\right)}
$$

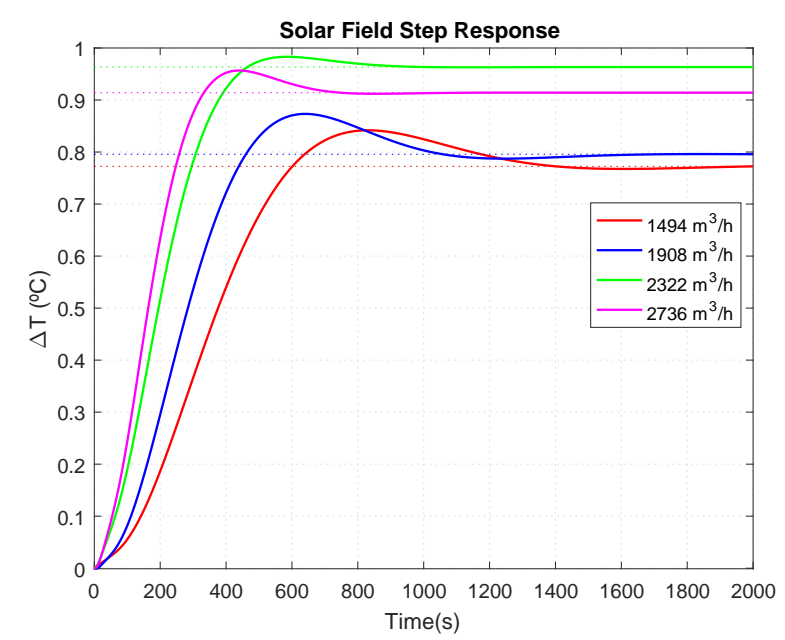

Figure 2 Solar field step response of linear models. Output increments when unitary steps are applied to the input.

$P_{c p}$ can be approximated by $1.868 \times 10^{6} \mathrm{~kJ} /{ }^{\circ} \mathrm{C}$ and $S$ takes the value of $3427 \mathrm{~m}^{2}$ (Camacho et al., 1997, Geyer et al., 2002). The control scheme, see Fig. 3, works as follows: The GS-GPC receives the temperature set-point for the solar field and the current mean temperature and computes a virtual reference temperature, $T_{\text {ref }}$, for the FF. The FF computes oil flow taking into account the virtual reference and the measured disturbances to track the desired set-point. Since the GS-GPC + FF scheme is considering a global model by one loop, the calculated flow-rate is for one loop. The GS-GPC + FF scheme is presented in Fig. 3 where $Q_{f f}$ represents the global flowrate for the complete field and $Q$ is the measured flow-rate.

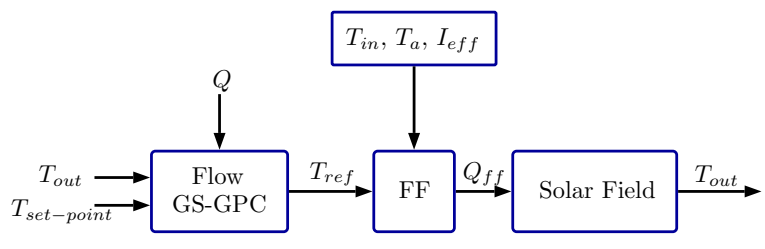

Figure 3 GS-GPC + FeedForward control scheme.

Let's assume that the model is perfect. In this case the virtual reference would be equal to the desired set-point in steady-state. Since the model is not perfect, the virtual reference will not be equal to the desired set-point.

Fig. 4 shows a simulation of the control scheme with a sampling time of $T s=30 s$ (Camacho et al., 1997), where all the loops have the same parameter values. To compute the estimation of the flow to be applied to the whole solar 
field, the temperature to be controlled is the mean of all the loops. Geometric efficiency $n_{o}$ is considered to be the same for all the loops and is computed by the equations described in (Camacho et al., 1997). Optical efficiency $K_{\text {opt }}$ used in the series FF controller is the mean of the estimation obtained for each loop.
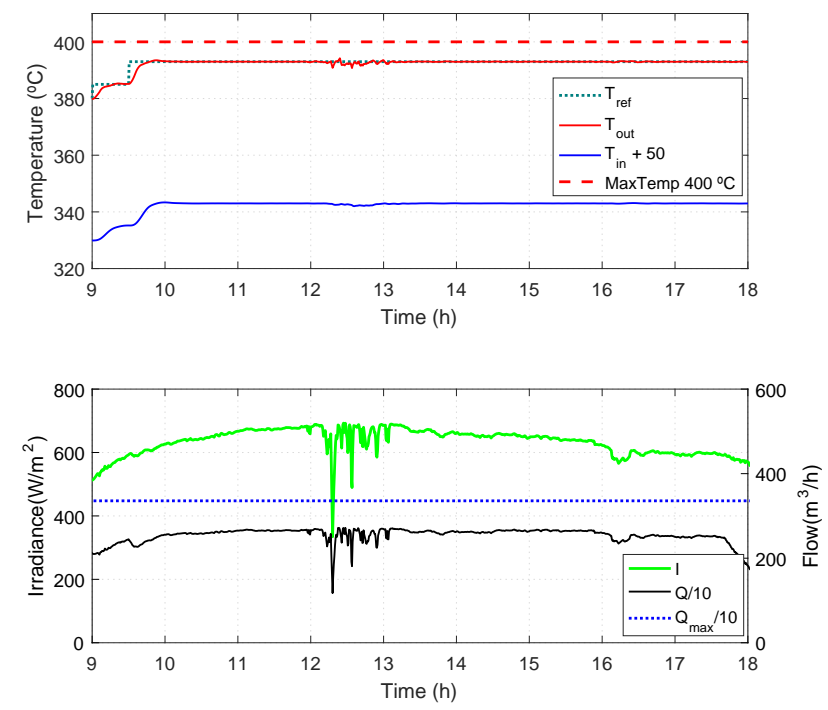

Figure 4 GS-GPC + FF tracking results (medium irradiance)

\section{Fourth collector defocus GPC}

As presented in Fig. 4, the GS-GPC in series with a FF correctly tracks the field outlet temperature set-point because this simulation corresponds to a medium irradiance day. Flow-rate in this simulation is close to the maximum. In a high irradiance day flow-rate control is not enough to control the outlet temperature and, thus, temperature will soar up. Fig. 5 shows this scenario. It can be observed that the flow-rate is at its maximum and the outlet temperature starts to increase.

Generally, parabolic trough plants have safety mechanisms to prevent the outlet temperature of a loop exceeding the allowed maximum. This security procedure is carried out by defocusing the collectors, causing the loop to cool down due to the decrease in the amount of effective radiation received by the tube. The defocusing of the fourth collector is, generally, applied to simply prevent the oil temperature from exceeding a maximum temperature of $400{ }^{\circ} \mathrm{C}$. This control action is carried out by modifying the angle of the collector. Moreover, fourth collector defocus of a loop is independent of the flow rate and the defocus actions of other loops since each loop is different and their parameters may vary amongst themselves so that not all loops will be at the same temperature. In this paper an Event based GS-GPC is proposed for fourth collector defocus control. An EGS-GPC per loop is needed and it is also necessary to apply a temperature set-point.
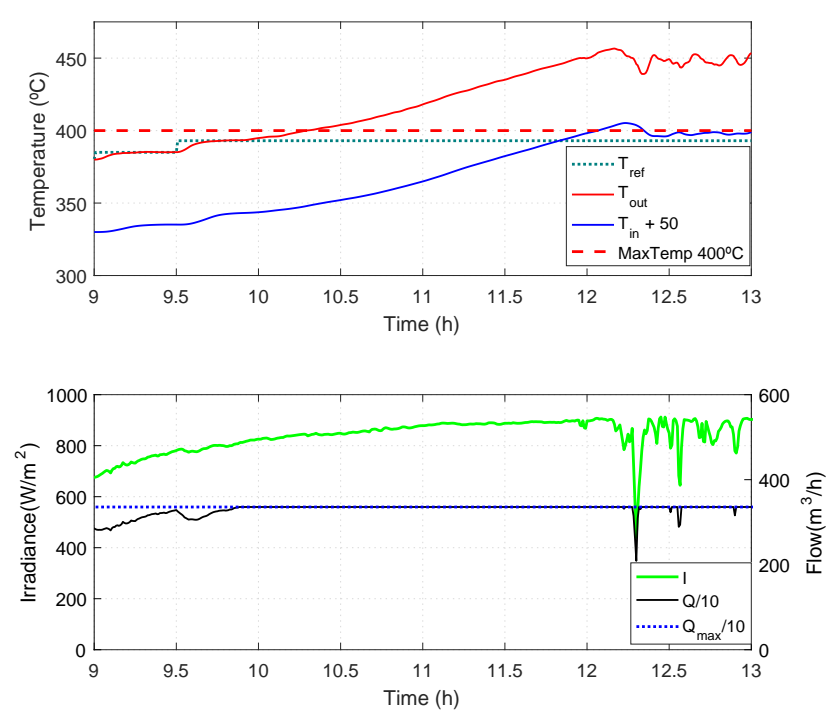

Figure 5 GS-GPC + FF. Flow-Rate at maximum due to high irradiance leading to temperature limit violation.

A function that relates the defocus angle to collector efficiency is needed. The approximation of this function to design the GS-GPC is presented in Fig. 6, (Goswami et al., 2000). Since the function is non-linear, the gainscheduling will be designed at 9 different points of defocus angle $(0.5,1,1.5,2,2.5,3,3.5,4$ and 4.5 degrees $)$. From a certain defocus angle, efficiency begins to decrease rapidly, since rays no longer reach the tube. Moreover, the plant responds differently depending on the flow-rate, so defocus linear models will not be the same for all flow-rates. To improve the performance of collector defocus GS-GPC, 9 linear models are obtained for each of the flow-rate points where Flow GS-GPC has been designed (1494, 1908, 2322 and $\left.2736 \mathrm{~m}^{3} / \mathrm{h}\right)$. The linear models obtained are presented in Figs. 7, 8, 9 and 10.

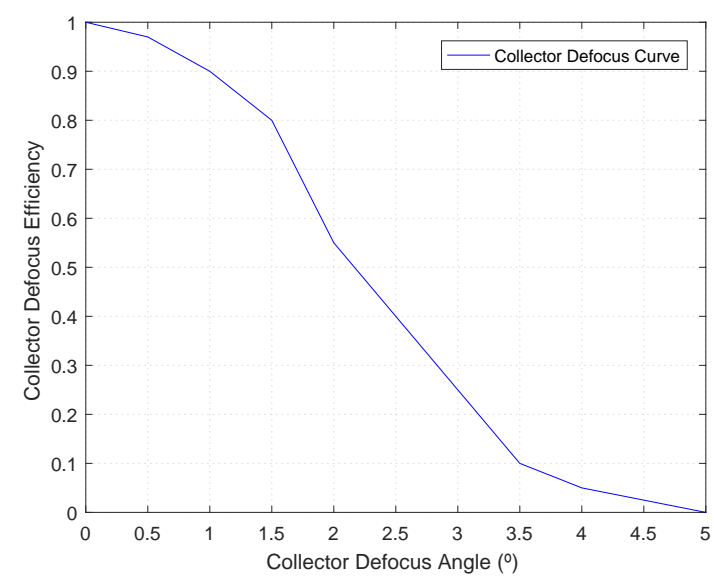

Figure 6 Efficiency - Defocus angle curve. 


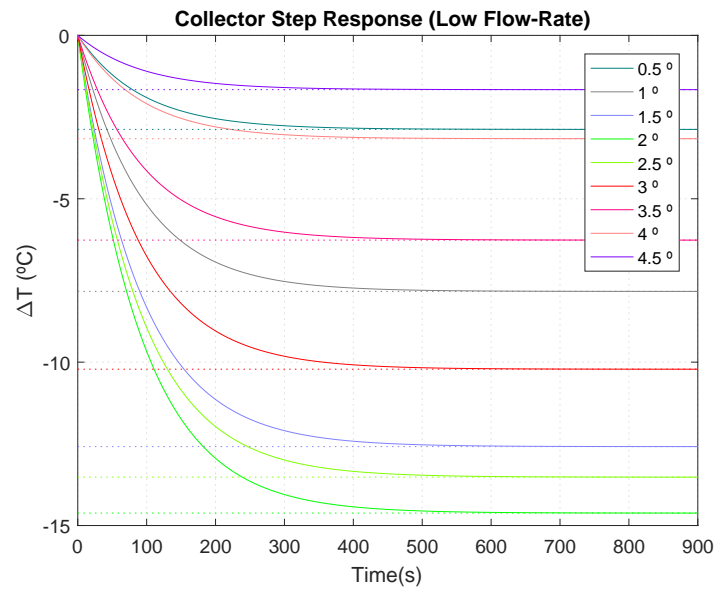

Figure 7 Low flow-rate collector step response of linear models.

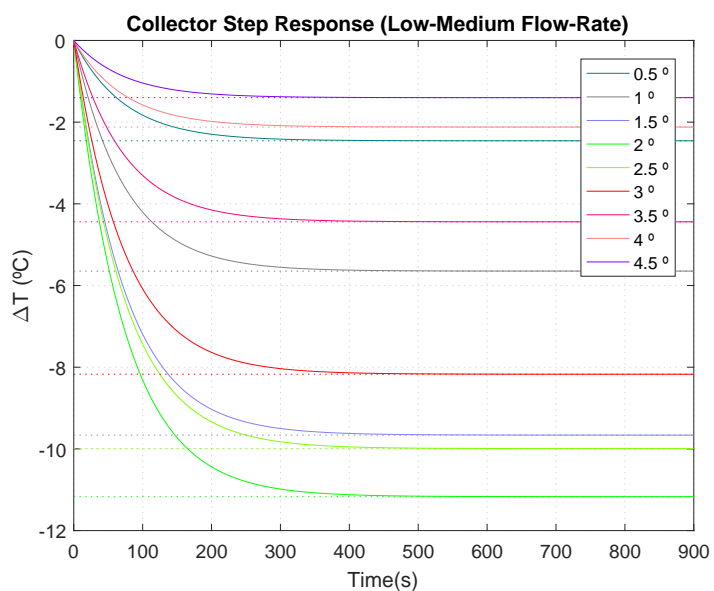

Figure 8 Low-Medium flow-rate collector step response of linear models.

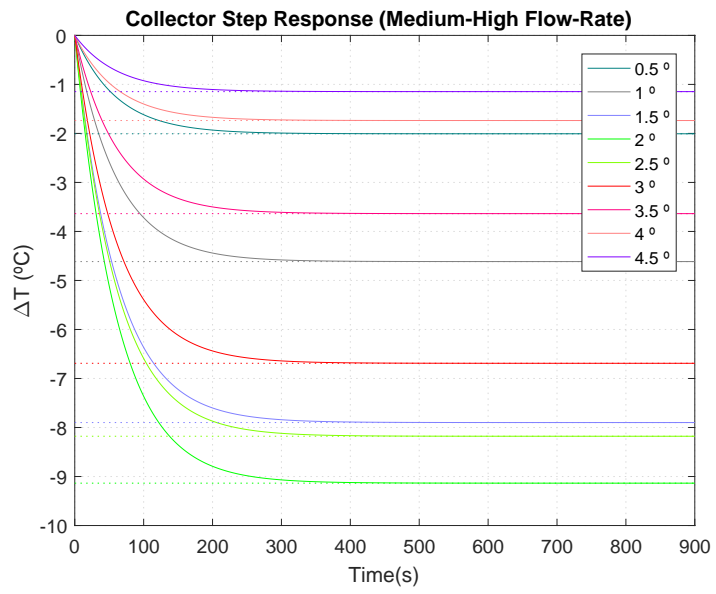

Figure 9 Medium-High flow-rate collector step response of linear models.

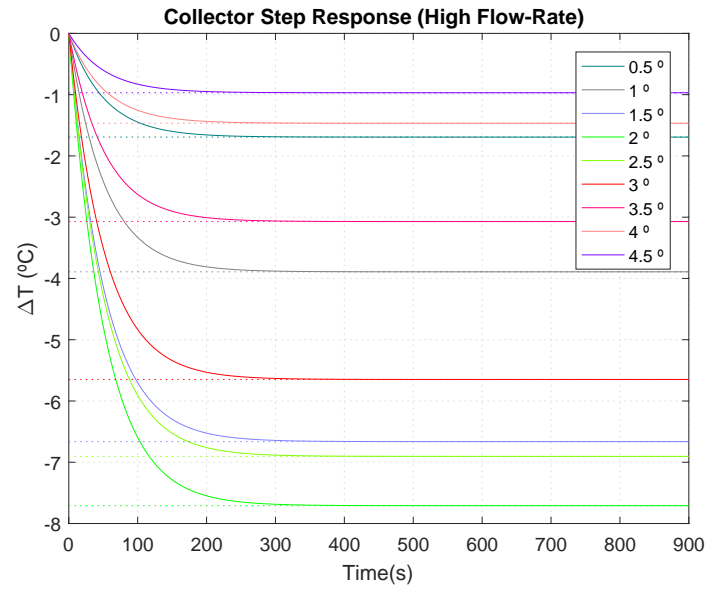

Figure 10 High flow-rate collector step response of linear models.

For the temperature set-point, it is easier to apply a temperature set-point of $393{ }^{\circ} \mathrm{C}$ to each loop given that it is the nominal working temperature. However, since the loops may vary in reflectivity, tube efficiency and form factor, among others, some loops may be colder than others. In the hotter loops, the defocus would be activated for a temperature reference of $393{ }^{\circ} \mathrm{C}$ and the other loops would be at a slightly lower temperature. This could cause a conflict with flow-rate control at certain times. To avoid this, an event based heuristic is applied to send different temperature set-points to the GS-GPC. This heuristic is to detect an event based on flow-rate, outlet temperature, power limitation and to apply the appropriate set-point:

1. If $P W_{T S O}(k)$ or $\left.\left(Q(k)>Q_{\text {high }} \& T_{\text {out }}(k)>T_{\text {high }}\right)\right)$

- Temperature set-point $=T_{r e f-s a t}$

2. Else

- If $Q<Q_{\text {low }}$ or $T_{\text {out }}<T_{\text {low }}$

- Temperature set-point $=T_{\text {ref-nosat }}$

3. If $P W_{T S O}(k-1) \& ! P W_{T S O}(k)$

- Temperature set-point $=T_{\text {ref-nosat }}$

In this work, the chosen values for previous set-points are: $Q_{\text {high }}=3150 \mathrm{~m}^{3} / \mathrm{h}, Q_{\text {low }}=3060 \mathrm{~m}^{3} / \mathrm{h}, T_{\text {high }}=395$ ${ }^{\circ} \mathrm{C}, T_{\text {low }}=391{ }^{\circ} \mathrm{C}, T_{\text {ref-nosat }}=396{ }^{\circ} \mathrm{C}$ and $T_{\text {ref-sat }}=$ $393{ }^{\circ} \mathrm{C}$. Rules work by detecting the state of the plant. Rule (1) detects if there is a power limitation or if the plant is saturated. This occurs when the flow-rate is close to the maximum by checking it with $Q_{h i g h}$ and the outlet temperature is over $T_{h i g h}$. If the plant is saturated or in power limitation $T_{\text {ref-sat }}$ is applied to the defocus GS-GPC as temperature set-point. Rule (2) detects if the plant is not saturated. This will happen when the flow-rate is far from the maximum, $Q_{\text {low }}$, or if the outlet temperature is below $T_{\text {low }}$. Since flow-rate is low or the field outlet temperature is far from the maximum allowed, the temperature setpoint applied to defocus the loops is higher, $T_{\text {ref-nosat }}$. The last rule detects if the power limitation was removed 
and it will also apply $T_{\text {ref-nosat }}$. This approach is to take advantage of the hottest loops to maintain the field at high temperature. If the plant is not saturated, a set-point of $396{ }^{\circ} \mathrm{C}$ is applied. In this way, if there are some colder loops, they would be compensated for by the hotter loops. As the plant approaches saturation, the flow-rate begins to become close to its maximum, so a $393{ }^{\circ} \mathrm{C}$ set-point is applied, since it is not possible to increase the flow-rate in saturation and all loops will eventually end up being defocused. The control scheme that includes the defocus of the fourth collector is presented in Fig. 11.

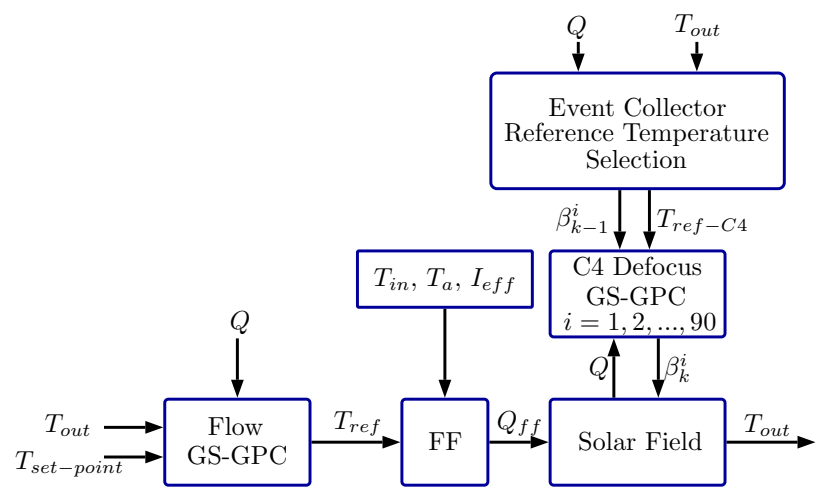

Figure 11 Flow GS-GPC + FF + C4 EGS-GPC control scheme.

In Figs. 12 and 13, results of the simulation of the flow GS-GPS adding the event based defocus GS-GPC is shown. In this simulation, where irradiance is high, it can be seen how by defocusing the fourth collector it is possible to correctly maintain the temperature below the maximum limit.
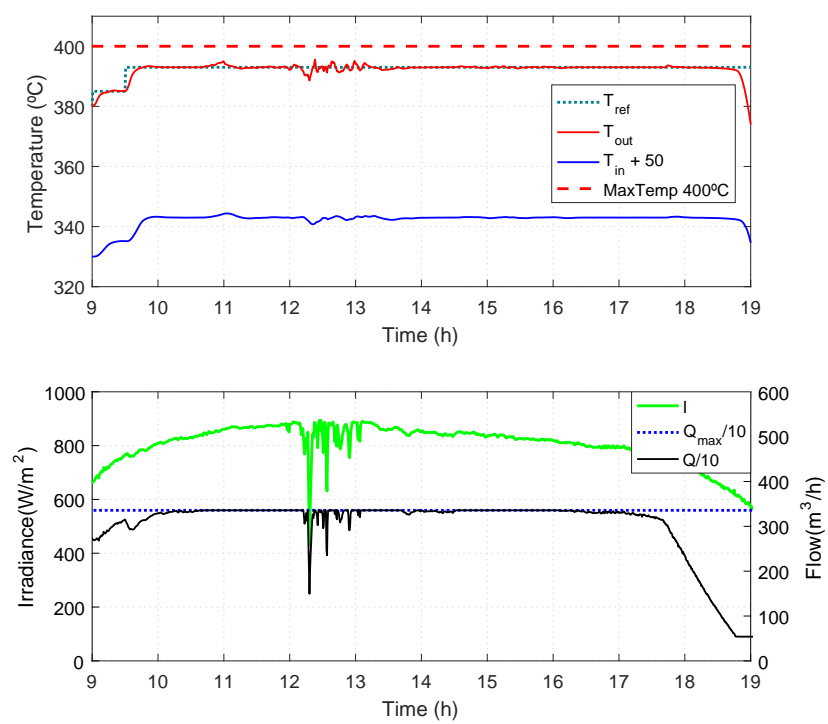

Figure 12 Flow GS-GPC + FF + C4 EGS-GPC loop temperature tracking results. Top plot: field fluid temperatures. Bottom plot: Irradiance and flow-rate.
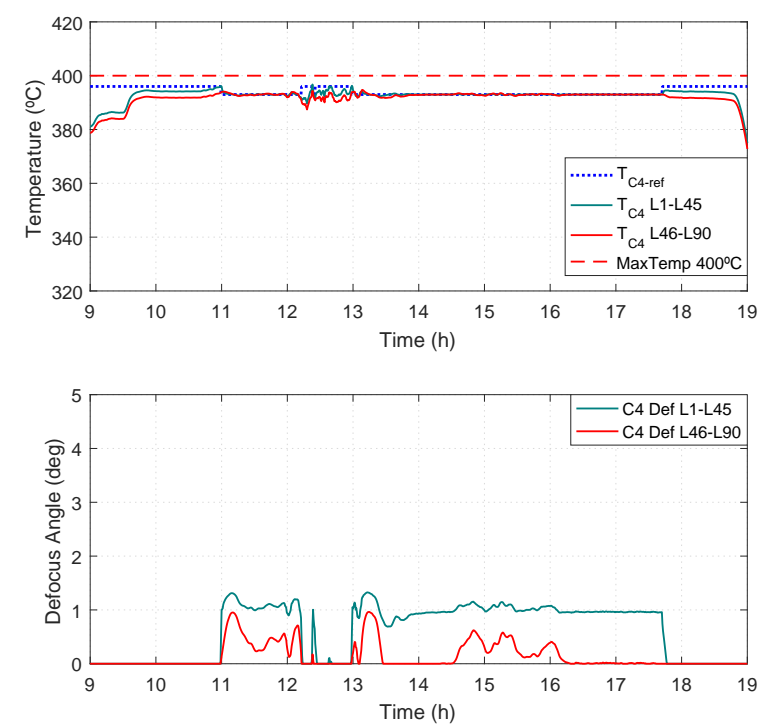

Figure 13 Flow GS-GPC + FF + C4 EGS-GPC loop temperature tracking results. Top plot: loop fluid temperatures. Bottom plot: Fourth Collector defocus angle control actions.

In general, in normal situations, defocusing the fourth collector is the only active control in commercial plants to avoid oil temperature from reaching the limit indicated by the manufacturer.

\section{Power generation event based GPC}

It has previously been observed that to obtain a power of approximately $50 \mathrm{MW}$, an oil flow-rate of approximately $655 \mathrm{~kg} / \mathrm{s}\left(3350 \mathrm{~m}^{3} / \mathrm{h}\right)$ is needed at nominal operation, $393{ }^{\circ} \mathrm{C}$. However, the power cycle is not linear with the flow-rate and its dynamic behavior varies according to the working point of flow-rate when working at 393 ${ }^{\circ} \mathrm{C}$. At nominal temperature, the power cycle can be approximated as a first-order system with different time constants depending on the oil flow-rate (Schenk et al., 2015; Montañés et al., 2018)

Upon receiving a TSO power limitation, the plant will have time to adjust to the set electric power limit. In general, it is a complex operation for an operator, given that the flow-rate must decrease in order to reach the power set-point in a given time. Since the power cycle can be modeled as linear systems, an Event based GS-GPC is proposed to control the electric power generated by the plant. In this case, the event is none other than a power limitation determined by the TSO. The use of MPC is a great advantage in this case, since a power reference ramp for the available time can be used to obtain a better response due to the sliding horizon. Generally, in many processes the set-point is fixed and future set-points are unknown. However, in this case, it is possible to take advantage of the use of the MPC sliding horizon since it is possible to create time ramp power set-points (future set-points). This will 
make better and smoother power set-point tracking than with a simple power step. Power limitations received by the TSO will be implemented as boolean variables, $T S O_{L}$ and $P W_{T S O}$, see section 4 . These variables will be set to true when the TSO limitation is received (down-ramp starts). $T S O_{L}$ will be set to false when TSO limit has been removed and $P W_{T S O}$ will be set to false in two situations: (1) when the up-ramp is finished (TSO limit has been removed and plant has reached $50 \mathrm{MW}$ again); (2) if during the up-ramp the field outlet temperature is less than $391{ }^{\circ} \mathrm{C}$ which means the plant cannot reach $50 \mathrm{MW}$ at nominal outlet temperature, see Fig. 14.
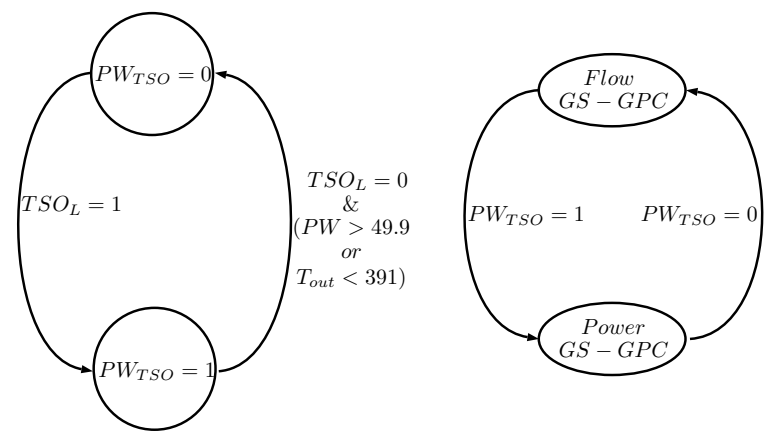

Figure 14 Power Limitation Event block state graph.

To design the power GS-GPC control, first order systems have been modeled at 3 flow-rate working points 167.06, 334.1 and $501.16 \mathrm{~kg} / \mathrm{s}\left(855,1710\right.$ and $\left.2565 \mathrm{~m}^{3} / \mathrm{h}\right)$ at nominal temperature $393{ }^{\circ} \mathrm{C}$, see Fig. 15. The input of the power cycle linear models is the flow-rate $(\mathrm{kg} / \mathrm{s})$ and the output is the power $(M W)$.

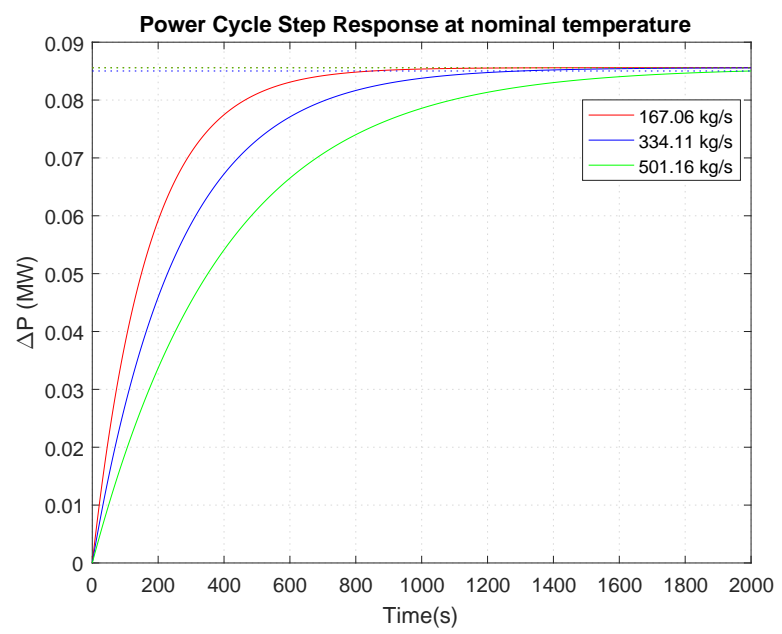

Figure 15 Power cycle step response of linear models. Output increments when unitary steps are applied to the input.

Fig. 15 shows the output increment when a unitary step is applied to the input at the different operating points. It can be seen that the differences in dynamics are significant. The design of the GS-GPC is done in the same way as in the cases of the flow-rate and defocus.
In order to reduce the electric power generated, the oil flow-rate will be considerably reduced, though the temperature will not decrease since the operation of the plant must remain at a nominal temperature of $393{ }^{\circ} \mathrm{C}$. As previously mentioned, decreasing the flow-rate causes an increase in the outlet temperature of the loops that is controlled by the fourth collector defocus EGS-GPC. However, as can be seen in Figs. 12 and 13 (defocus of the fourth collector), where there is no power limitation and the defocus controller is close to saturation, the defocusing controller will not be able to keep the oil temperature below the temperature limit in cases of power limitation. Another level of defocus control is needed, the third collector defocus.

\subsection{Third collector defocus GPC}

Defocusing of the third collector will be necessary only during a power limitation operation since the fourth collector controller will not be able to control the outlet temperature by itself. For the control of the third collector of each loop, a GS-GPC event based is proposed, where the event in this case is the limitation of generated electric power. The GS-GPC is designed in the same way as in the case of the fourth collector. The linear models for gain scheduling the third collector are the same models previously calculated for the fourth collector, since they are collector models.

Since defocusing the third collector is not necessary except in power limitation, the event to be detected is the arrival of a power restriction. The temperature reference is different than in the fourth collector. The simplest option would be to divide the desired thermal difference in the loop $\left(100{ }^{\circ} \mathrm{C}\right)$ by the 4 collectors, which would result in a set-point of $375^{\circ} \mathrm{C}$ for the third collector outlet temperature. However, the temperature set-point for the third collector has been chosen based on the control action of the fourth collector.

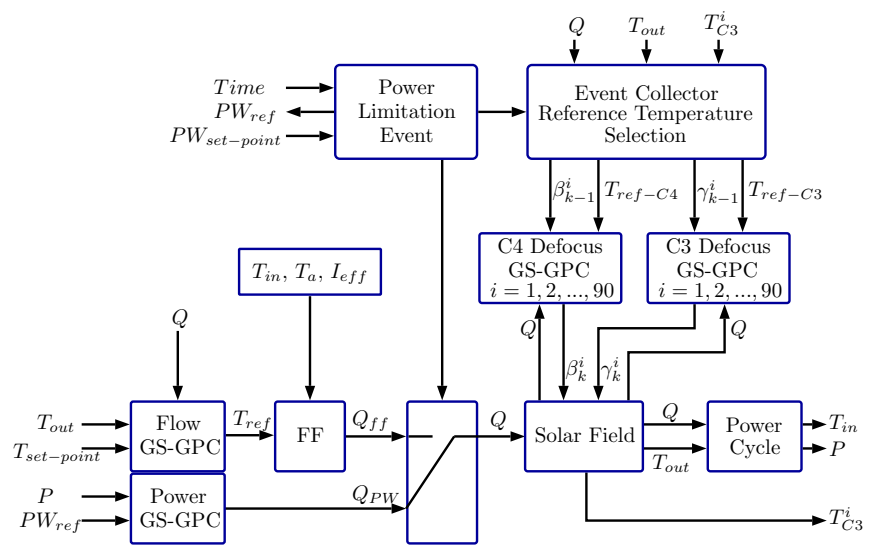

Figure 16 Flow GS-GPC + FF + C4/C3 EGS-GPC + Power EGSGPC control scheme.

As previously mentioned, the defocusing curve is nonlinear. It can be seen how the curve has a steep slope 
around 2-3 degrees of defocus. Beyond 3 degrees the efficiency approaches zero, which means very little control ability. The temperature set-point that the third collector must follow has been chosen around this defocusing angle. In this way, the third collector does not defocus until the GS-GPC of the fourth collector begins to lack control capacity. By simulation, it has been obtained that the approximate temperature value at the outlet of the third collector is $385{ }^{\circ} \mathrm{C}$ when the fourth collector is defocus around 3 degrees.

During the power reference up-ramp, the third collector is still active and, since flow-rate is increased, in order to increase power, the temperature of the third collector will decrease causing the GS-GPC to decrease the control action until 0 degrees of defocus is reached. At the end of the up-ramp, the third collector will not be out of focus and only the fourth EGS-GPC will be active. Similarly, when the up-ramp is terminated, the power EGS-GPC is deactivated and the flow-rate GS-GPC is activated once more, in order to control the field outlet temperature at $393{ }^{\circ} \mathrm{C}$.

\section{Results}

In this section, results from simulations are presented. The simulations were carried out in scenarios with power limitations of one hour and half hour time constraints from the TSO. A power limitation event has been simulated without applying control of the third collector defocus to show the reader what would happen in this case and why it is important to apply the defocus to the third collector in cases of power limitation. Likewise, scenarios in which half the solar field has an overall efficiency of 0.7776 (45 loops) and the other half an efficiency of 0.7607 (45 loops) have been simulated. It has been done in this way since, although there is no problem in simulating and controlling a field with 90 loops, it is not possible to represent the control actions of 90 collectors in the same or in several graphs due to the space that this would take. A scenario in which 10 loops have different efficiencies has been simulated, to show the results of the defocus control actions of the third and fourth loop collectors.

First, it is shown that the third control may be unnecessary if the power set-point is not too low. In this scenario, a simulation of a $40 \mathrm{MW}$ limitation has been performed. Secondly, a scenario with a higher power limitation is simulated to show why the third collector defocus is necessary in case of power limitations.

Figures 17 and 18 show the results obtained from the proposed control scheme when receiving a power limitation of $40 M W$ with a one hour time constraint. At 11:40 a set-point of $40 M W$ is received from the TSO. At this point the plant is operating in flow-rate GS-GPC at 50 $M W$ and $393{ }^{\circ} \mathrm{C}$. Upon receiving the command, it can be seen how the plant begins to decrease the flow-rate to track the power reference indicated by the ramp that has been generated by the block "power cycle event".
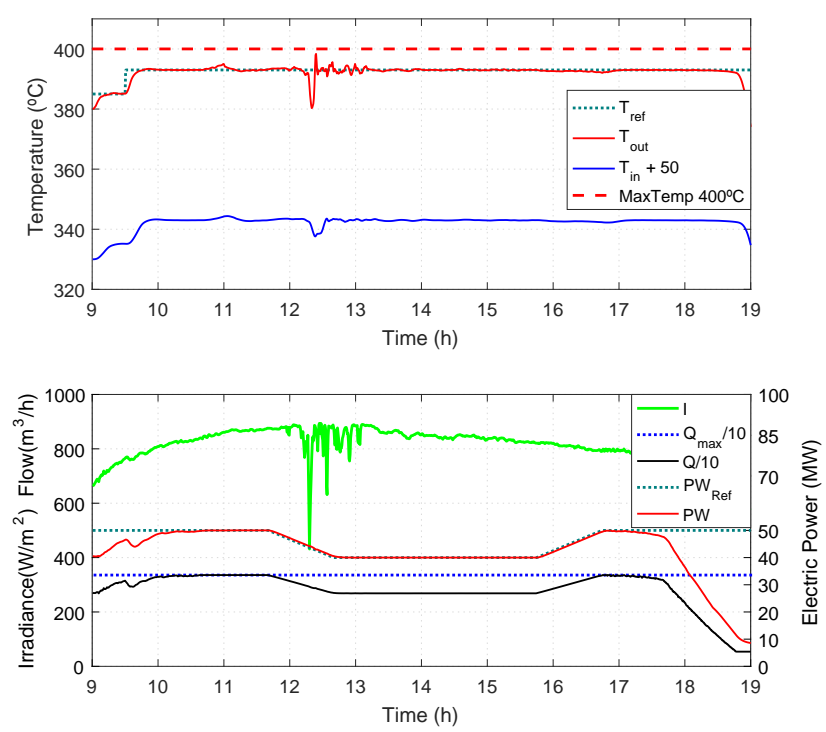

Figure 17 Flow GS-GPC + FF + C4 EGS-GPC + PW EGS-GPC, 40 $M W$ TSO limitation at 11:40am and TSO limitation off at 15:45pm (60 min ramp). Top plot: field fluid temperatures. Bottom plot: Irradiance, flow-rate and electric power.
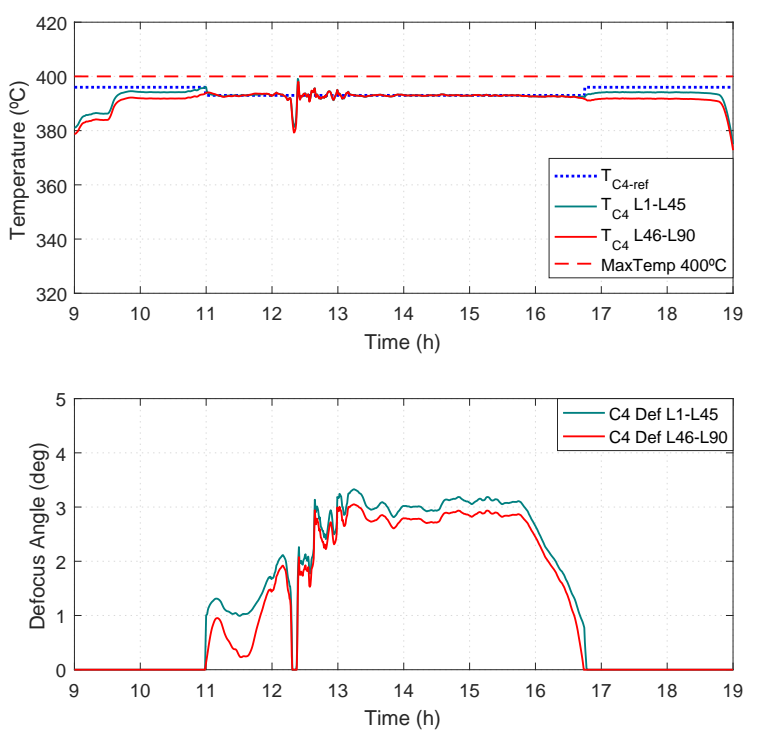

Figure 18 Flow GS-GPC + FF + C4 EGS-GPC + PW EGS-GPC, 40 $M W$ TSO limitation at 11:40am and TSO limitation off at 15:45pm (60 min ramp). Top plot: loop fluid temperatures. Bottom plot: Fourth Collector defocus angle control actions.

Since the flow rate decreases, the fourth collector defocus EGS-GPC is responsible for maintaining the loops outlet temperature at $393{ }^{\circ} \mathrm{C}$, and thus the field outlet temperature also, since the plant is in power limitation. Fig. 18 shows how the fourth collector EGS-GPC is able to correctly track the temperature reference.

Figs. 19 and 20 present the results of a simulation 
where a $30 M W$ electric power constraint is received and the flow-rate control and fourth collector defocus are not sufficient to maintain the outlet temperature at the nominal set-point.
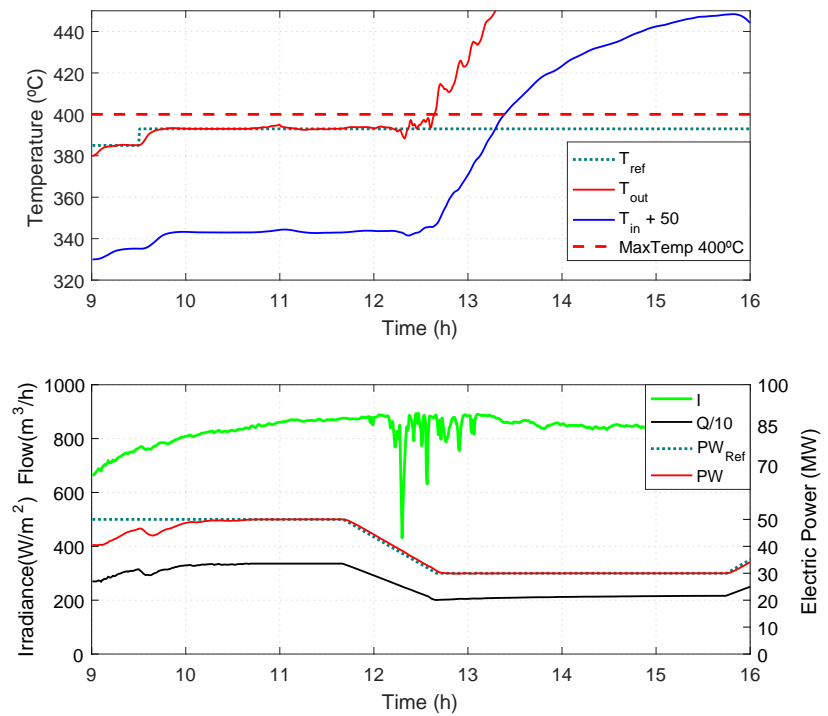

Figure 19 Flow GS-GPC + FF + C4 EGS-GPC outlet temperature limit violation. Fully defocused fourth collector. Top plot: field fluid temperatures. Bottom plot: Irradiance, flow-rate and electric power.
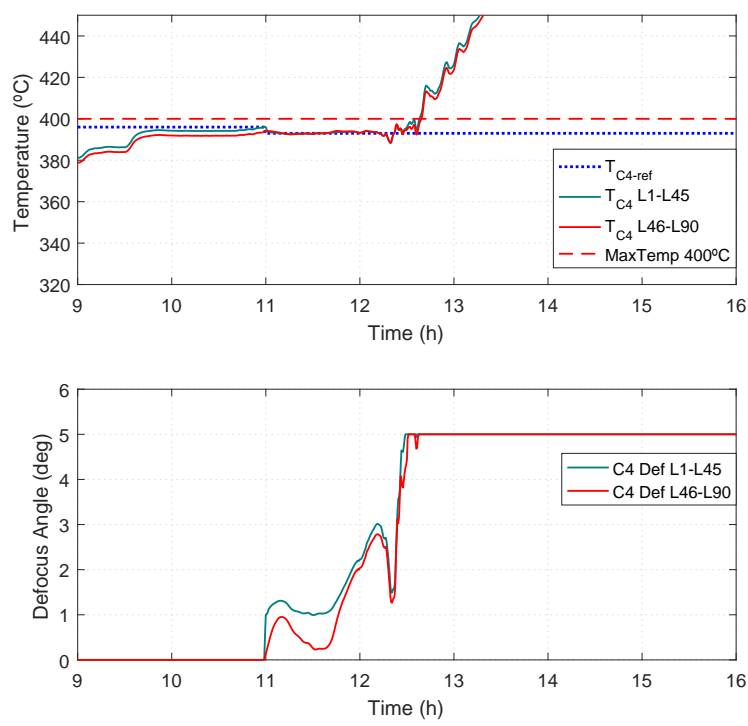

Figure 20 Flow GS-GPC + FF + C4 EGS-GPC outlet temperature limit violation. Fully defocused fourth collector. Top plot: loop fluid temperatures. Bottom plot: Fourth collector defocus angle.

The plant produces $50 M W$ approximately at receival of the power set-point. In Fig. 19, it can be observed how the temperature cannot be controlled at the desired temperature set-point due to the saturation of the fourth collector EGS-GPC control action, see Fig. 20.

Figs. 21, 22 and 23 show the results of the same scenario when the third collector controller is added to the control strategy.
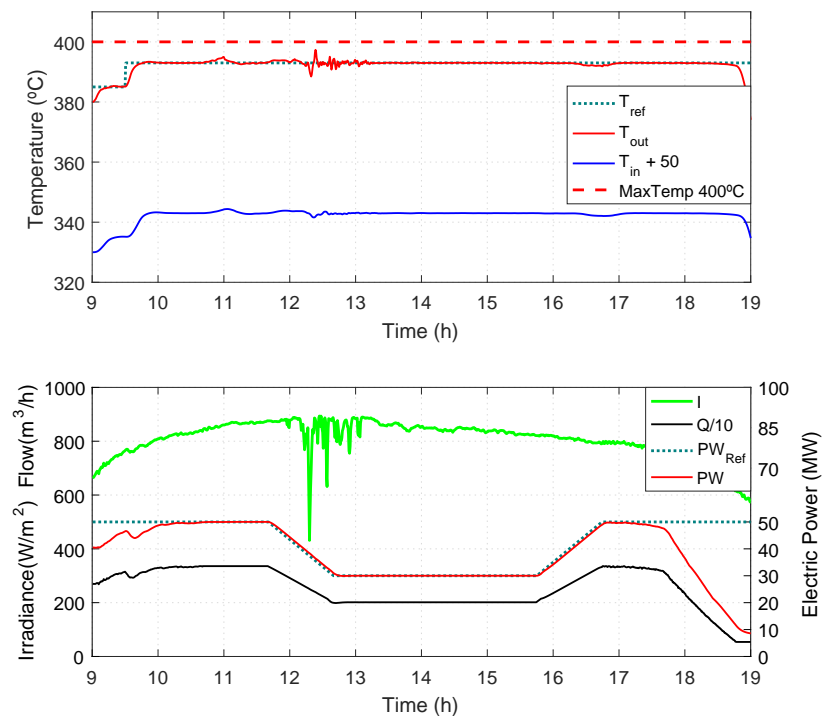

Figure 21 Flow GS-GPC + FF + C4/C3 EGS-GPC + PW EGSGPC, $30 M W$ TSO limitation at 11:40am and TSO limitation off at 15:45pm (60 min ramp). Top plot: field fluid temperatures. Bottom plot: Irradiance, flow-rate and electric power.
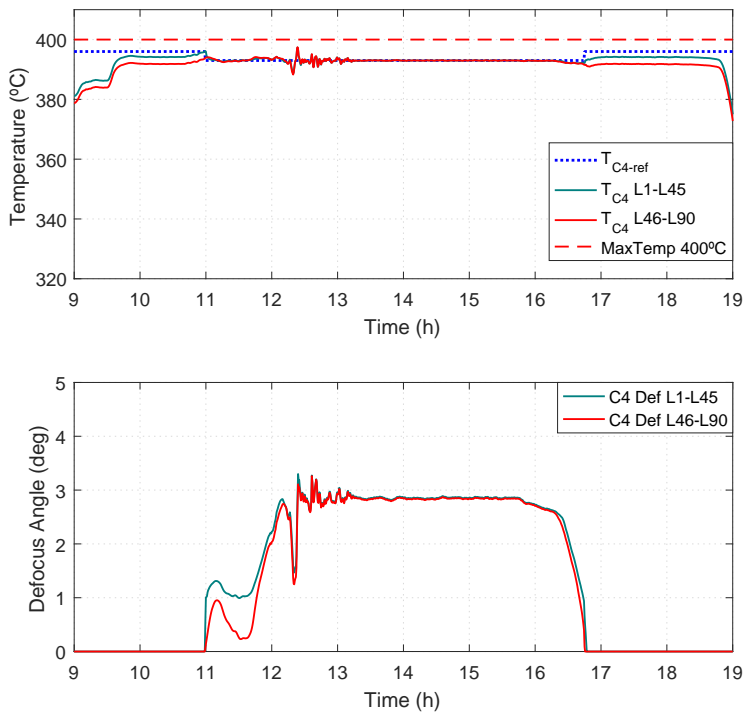

Figure 22 Flow GS-GPC + FF + C4/C3 EGS-GPC + PW EGSGPC, $30 M W$ TSO limitation at 11:40am and TSO limitation off at 15:45pm (60 min ramp). Top plot: loop fluid temperatures. Bottom plot: Fourth collector defocus angle.

It is clear that the third collector defocus helps to keep the outlet temperature of the field at the desired 
set-point. As previously commented, the third collector defocus starts to control when the outlet temperature of the third collector is close to $385{ }^{\circ} \mathrm{C}$.

In Fig. 22, it is possible to check that the fourth collector is at an angle control action in which it is still in control of the system. Both controllers react against the radiation perturbation and continue defocusing until power limitation is off at $15: 45 \mathrm{pm}$, see Figs. 22 and 23. Power is increased and the third collector defocus GS-GPC drops to 0 degrees (efficiency $=1$ ), see Fig. 23.
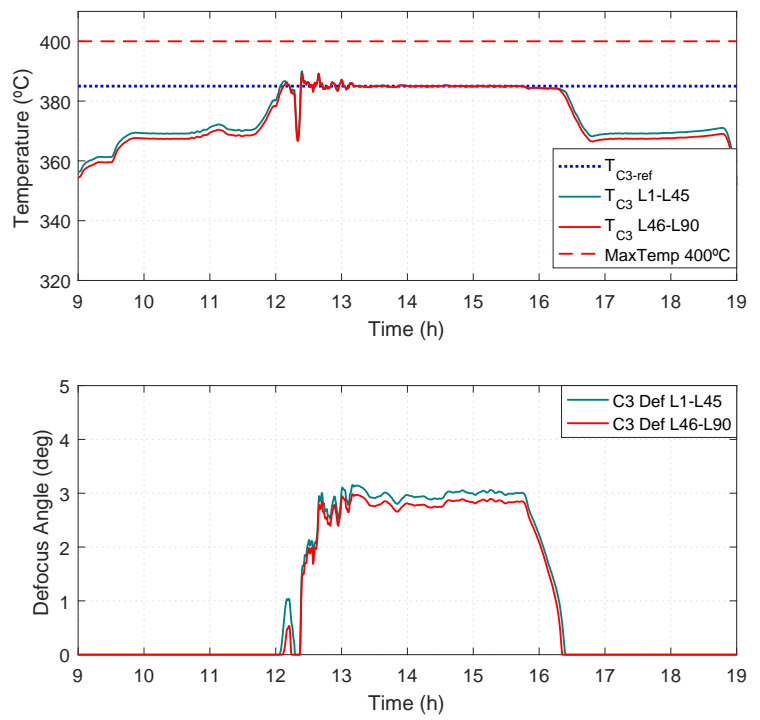

Figure 23 Flow GS-GPC + FF + C4/C3 EGS-GPC + PW EGSGPC, $30 M W$ TSO limitation at 11:40am and TSO limitation off at 15:45pm (60 min ramp). Top plot: loop fluid temperatures. Bottom plot: Third collector defocus angle.

In Figs. 24, 25 and 26, a scenario with a $40 M W$ power limitation has been simulated with two different time periods. First, a time period of one hour to bring down power is received. The second time period is when the limitation is removed. The plant has half an hour to return to maximum possible production.

Fig. 24 shows good performance of the controller tracking the power set-point in both ramps and the $40 \mathrm{MW}$ TSO power limitation. Flow-rate is decreased during the down ramp and increased in the up ramp. During power limitation, the fourth collector EGS-GPC is the main controller acting over the system and keeping the outlet temperature at the desired set-point. Third colletor GS-GPC is also active but with less control action in this case. Once again, it can be observed in Figs. 25 and 26, that the set-point tracking of fourth and third collectors has good performance.
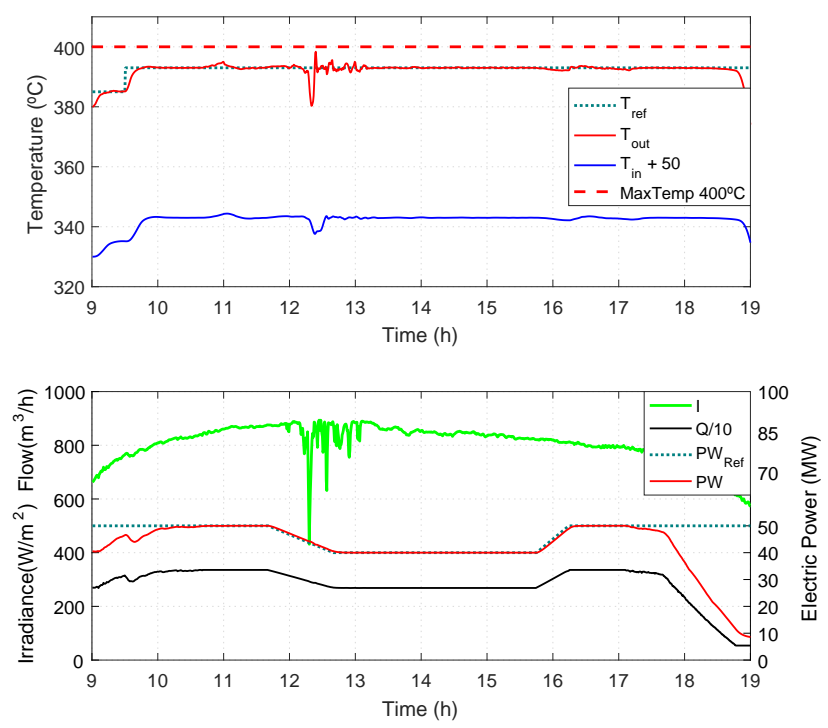

Figure 24 Flow GS-GPC + FF + C4/C3 EGS-GPC + PW EGSGPC, $40 M W$ TSO limitation at 11:40am (60 min ramp) and TSO limitation off at 15:45pm (30 min ramp). Top plot: field fluid temperatures. Bottom plot: Irradiance, flow-rate and electric power.
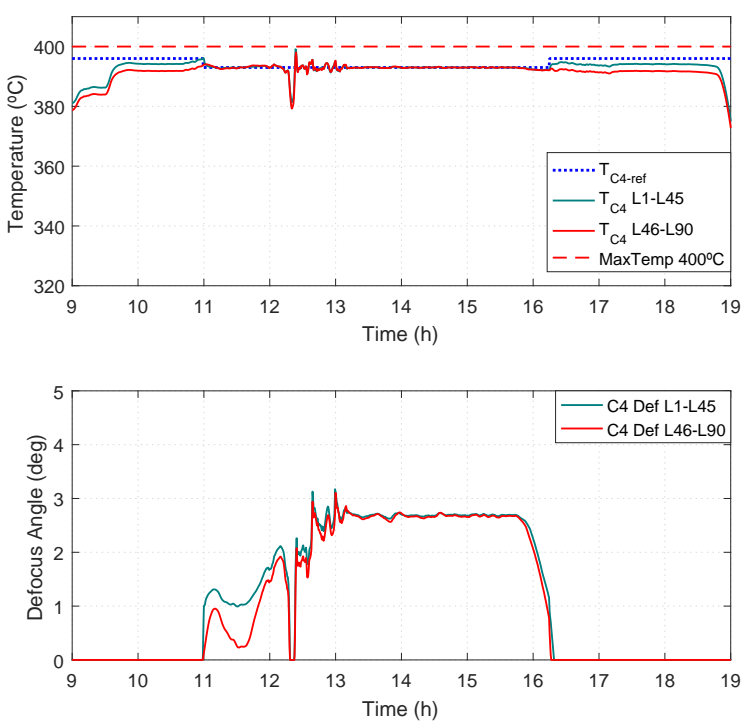

Figure 25 Flow GS-GPC + FF + C4/C3 EGS-GPC + PW EGSGPC, $40 M W$ TSO limitation at 11:40am (60 min ramp) and TSO limitation off at 15:45pm (30 min ramp). Top plot: loop fluid temperatures. Bottom plot: Fourth collector defocus angle control actions.

The last scenario shown in this section is a $30 \mathrm{MW}$ power limitation, again with two time periods for the ramps and a set of different reflectivities for ten loops, to show the behaviour of the fourth and third controller applied to each loop. This scenario is shown in Figs. 27, 28 and 29. Power tracking is presented in Fig. 27. It can be seen that the outlet temperature of the field is within the safe limits 
at any given moment. Fig. 28 shows the fourth collector EGS-GPC control actions for the 10 loops and the rest of the field. It can be observed that loops have different control actions, since every loop has a different efficiency and therefore different outlet temperatures. Outlet temperatures of each loop are also within the safety limits and follow the set-point. Fig. 29 shows the third collector GSGPC control actions of each loop. In the same way as the fourth collector, the behaviour is different for each loop for the same reason, each loop has its own controller.
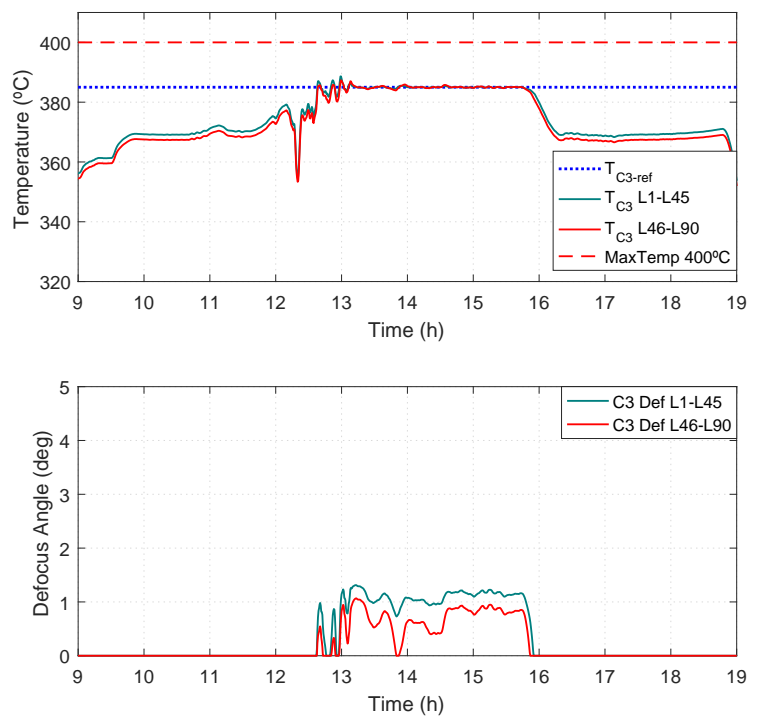

Figure 26 Flow GS-GPC + FF + C4/C3 EGS-GPC + PW EGSGPC, $40 M W$ TSO limitation at 11:40am (60 min ramp) and TSO limitation off at 15:45pm (30 min ramp). Top plot: loop fluid temperatures. Bottom plot: Third collector defocus angle control actions.

Table 3

Simulated Loop Efficiencies.

\begin{tabular}{llllll}
\hline Loop Number & L1 & L7 & L11 & L23 & L33 \\
\hline Global Efficiency & 0.7776 & 0.7607 & 0.7525 & 0.7783 & 0.7865 \\
\hline Loop Number & L47 & L61 & L74 & L81 & L89 \\
\hline Global Efficiency & 0.7857 & 0.7519 & 0.7445 & 0.7910 & 0.7819 \\
\hline
\end{tabular}
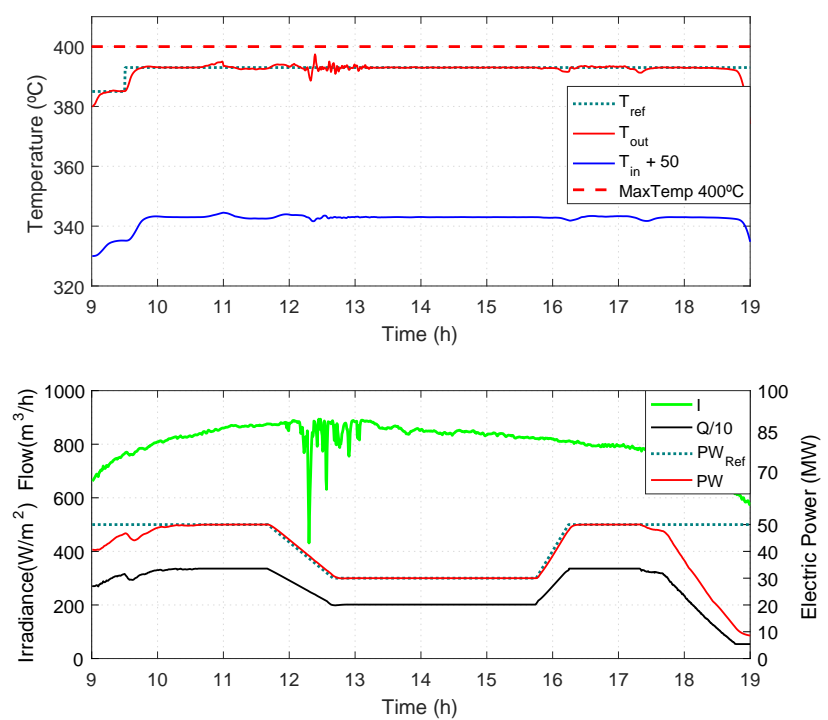

Figure 27 Flow GS-GPC + FF + C4/C3 EGS-GPC + PW EGSGPC, $30 M W$ TSO limitation at 11:40am (60 min ramp) and TSO limitation off at 15:45pm (30 min ramp). Top plot: field fluid temperatures. Bottom plot: Irradiance, flow-rate and electric power.
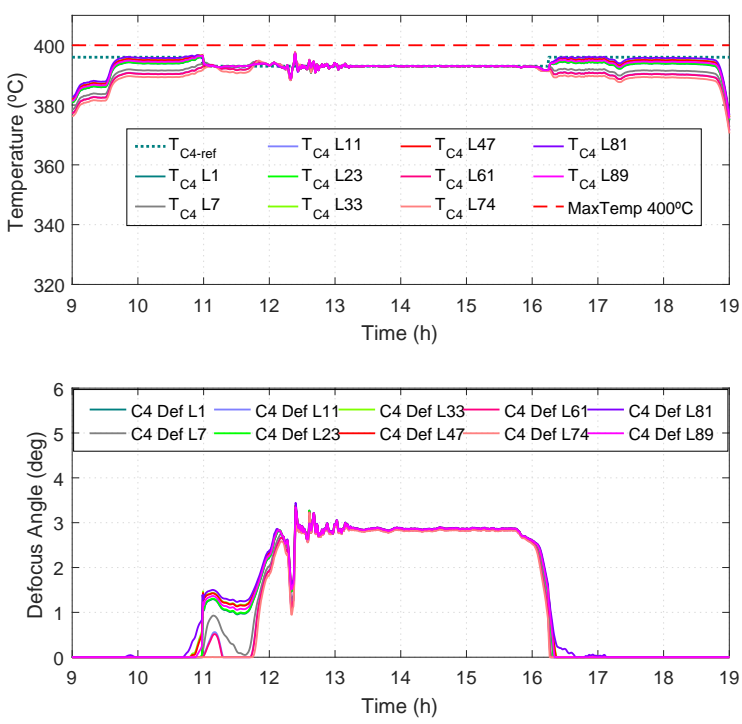

Figure 28 Flow GS-GPC + FF + C4/C3 EGS-GPC + PW EGSGPC, $40 M W$ TSO limitation at 11:40am (60 min ramp) and TSO limitation off at 15:45pm (30 min ramp). Top plot: loop fluid temperatures. Bottom plot: Fourth collector defocus angle control actions. 

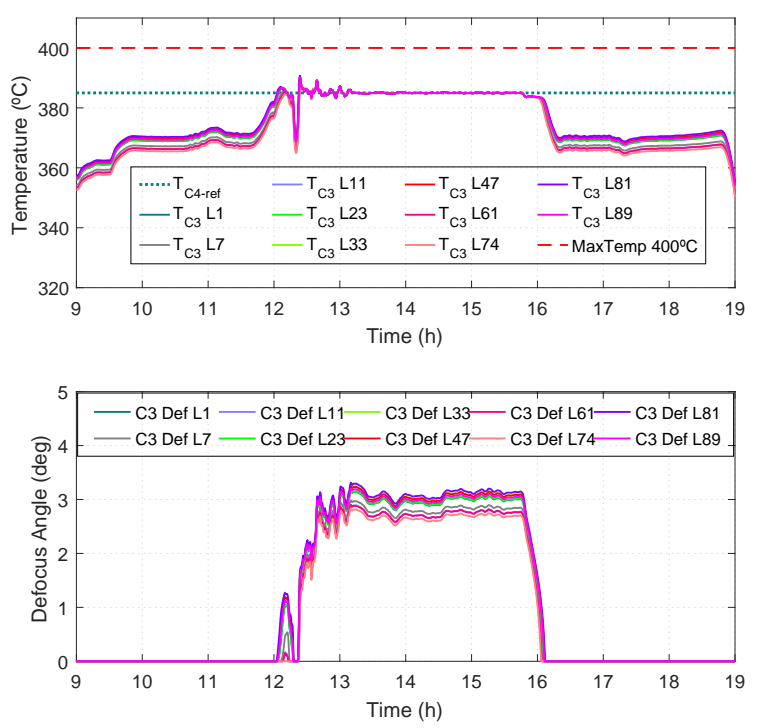

Figure 29 Flow GS-GPC + FF + C4/C3 EGS-GPC + PW EGSGPC, $40 M W$ TSO limitation at 11:40am (60 min ramp) and TSO limitation off at 15:45pm (30 min ramp). Top plot: loop fluid temperatures. Bottom plot: Third collector defocus angle control actions.

\section{Conclusions}

It is reasonable to assume that the optimization of a solar plant concept is directly related to terms of electric power generation. However, on some occasions, a commercial solar plant may receive a power limitation from the TSO. These commands make the plant move into an operation mode in which the objective is not maximum production. In these cases, the plant is forced to decrease its electric production and maintain the power set-point commanded by the TSO. Therefore a double objective problem arises: (1) temperature tracking and (2) generated power set-point tracking. The plant will have a time period to reduce its generated electric power to the set-point determined by the TSO. In this mode, the flow-rate should be decreased until the power set-point is achieved but at the cost of increasing the outlet temperature. To control the outlet temperature, a secondary control is needed. In this paper, an Event-Based Gain Scheduling Generalized Predictive Control (EGS-GPC) for electric power reference tracking when power limitations appear, has been proposed. In order to control the loops/field outlet temperature and to avoid exceeding oil degradation limits, an event based control strategy for defocusing the fourth and third collectors of each loop is developed with set-point changes depending on events. The linear models and control strategy have been obtained and designed by means of a $50 \mathrm{MW}$ parabolic trough plant model instead of the ACUREX model. Results show the proposed MPC strategy achieves power set-points determined by the TSO in the set time periods. The Power and Defocus EGS-GPCs are capable of performing good electric power tracking and nominal set-point tracking of loop outlet temperature avoiding oil degradation.

\section{Acknowledgments}

The authors would like to acknowledge the European Research Council for funding this work under Advanced Research Grant OCONTSOLAR (789051).

\section{References}

Alsharkawi, A., Rossiter, J. A., 2016. Dual mode mpc for a concentrated solar thermal power plant. IFAC-PapersOnLine. 11th IFAC Symposium on Dynamics and Control of Process Systems Including Biosystems DYCOPS-CAB. 49 (7), 260 - 265.

Alsharkawi, A., Rossiter, J. A., 2017. Towards an improved gain scheduling predictive control strategy for a solar thermal power plant. IET Control Theory Applications 11 (12), 1938-1947.

Alva, G., Liu, L., Huang, X., Fang, G., 2017. Thermal energy storage materials and systems for solar energy applications. Renewable and Sustainable Energy Reviews 68, 693 - 706 .

Andasol 1, 2018.

URL https://www.nrel.gov/csp/solarpaces/project_detail. cfm/projectID $=3$

Beschi, M., Dormido, S., Sanchez, J., Visioli, A., Yebra, L. J., Jul. 2014. Event-based pi plus feedforward control strategies for a distributed solar collector field. IEEE Transactions on Control Systems Technology 22 (4), 1615 - 1622.

Blanco, M., Miller, S., 2017. 1 - introduction to concentrating solar thermal (cst) technologies. In: Blanco, M. J., Santigosa, L. R. (Eds.), Advances in Concentrating Solar Thermal Research and Technology. Woodhead Publishing Series in Energy. Woodhead Publishing, pp. $3-25$.

Blanco, M. J., Santigosa, L. R., 2017. Advances in Concentrating Solar Thermal Research and Technology, 1st Edition. Woodhead Publishing.

Burkholder, F., Brandemuehl, M., Price, H., Netter, J., Kutscher, C., Wolfrum, E., 2007. Parabolic trough receiver thermal testing. In: Energy Sustainability, ASME 2007 Energy Sustainability Conference. pp. 961-970.

Camacho, E., Gallego, A., 2013. Optimal operation in solar trough plants: A case study. Solar Energy 95, $106-117$.

Camacho, E. F., Berenguel, M., Rubio, F. R., 1994. Application of a gain scheduling generalized predictive controller to a solar power plant. Control Engineering Practice 2 (2), 227-238.

Camacho, E. F., Berenguel, M., Rubio, F. R., 1997. Advanced Control of Solar Plants. Springer Science \& Business Media.

Camacho, E. F., Bordons, C., 2007. Model Predictive control, 2nd Edition. Springer-Verlag London.

Camacho, E. F., Rubio, F. R., Hughes, F. M., April 1992. Self-tuning control of a solar power plant with a distributed collector field. IEEE Control Systems 12 (2), 72-78.

Camacho, E. F., Samad, T., Garcia-Sanz, M., Hiskens, I., 2011. Control for renewable energy and smart grids. The Impact of Control Technology, Control Systems Society, 69-88.

Camacho, E. F., Soria, M. B., Rubio, F. R., Martínez, D., 2012. Control of Solar Energy Systems, 1st Edition. Springer-Verlag London.

Carmona, R., 1985. Analisis, modelado y control de un campo de colectores solares distribuidos con sistema de seguimiento en un eje. Ph.D. thesis. Universidad de Sevilla.

Desai, N. B., Bandyopadhyay, S., 2015. Optimization of concentrating solar thermal power plant based on parabolic trough collector. Journal of Cleaner Production 89, $262-271$.

Extresol 1, 2018.

URL https://www.nrel.gov/csp/solarpaces/project_detail. cfm/projectID $=10$

Geyer, M., Lüpfert, E., Osuna, R., Esteban, A., Schiel, W., Schweitzer, A., Zarza, E., Nava, P., Langenkamp, J., Mandelberg, 
E., Sep. 2002. Eurotrough - parabolic trough collector developed for cost efficient solar power generation. In: 11th SolarPACES International Symposium on Concentrated Solar Power and Chemical Energy Technologies.

Gil, P., Henriques, J., Cardoso, A., Carvalho, P., Dourado, A., March 2014. Affine neural network-based predictive control applied to a distributed solar collector field. IEEE Transactions on Control Systems Technology 22 (2), 585-596.

Goswami, D., Kreith, F., Kreider, J., 2000. Principles of Solar Engineering., 2nd Edition. Taylor \& Francis.

Guzmán, 2018.

URL https://www.nrel.gov/csp/solarpaces/project_detail. $\mathrm{cfm} / \mathrm{projectID}=18$

Helios 1, 2018.

URL https://www.nrel.gov/csp/solarpaces/project_detail. cfm/projectID $=47$

Ibersol 1, 2018.

URL https://www.nrel.gov/csp/solarpaces/project_detail. cfm/projectID $=18$

Kaxu Solar One, 2018.

URL https://www.nrel.gov/csp/solarpaces/project_detail. cfm/projectID $=245$

Kearney, D. W., 2007. Parabolic trough collector overview. Parabolic trough work-shop, NREL.

Khi Solar One, 2018.

URL https://www.nrel.gov/csp/solarpaces/project_detail. $\mathrm{cfm} /$ projectID $=244$

Khoukhi, B., Tadjine, M., Boucherit, M. S., May 2015. Nonlinear continuous-time generalized predictive control of solar power plant. Int. J. Simul. Multisci. Des. Optim. 6.

Lemos, J. M., Neves-Silva, R., Igreja, J. M., 2014. Adaptive Control of Solar Energy Collector Systems. Springer-Verlag.

Lima, D. M., Normey-Rico, J. E., Santos, T. L. M., 2016. Temperature control in a solar collector field using filtered dynamic matrix control. ISA Transactions 62, 39 - 49, sI: Control of Renewable Energy Systems.

Limón, D., Alvarado, I., Alamo, T., Ruiz, M., Camacho, E. F., 2008. Robust control of the distributed solar collector field acurex using mpc for tracking. IFAC Proceedings Volumes 41 (2), 958 - 963, 17th $\{$ IFAC $\}$ World Congress.

Lüpfert, E., Riffelmann, K., Price, H., Burkholder, F., Moss, T., May 2008. Experimental analysis of overall thermal properties of parabolic trough receivers. Journal of Solar Energy Engineering $130(2)$.

Majadas I, 2018.

URL https://www.nrel.gov/csp/solarpaces/project_detail. cfm/projectID $=9$

Montañés, R. M., Windahl, J., Palsson, J., Thern, M., 2018. Dynamic modeling of a parabolic trough solar thermal power plant with thermal storage using modelica. Heat Transfer Engineering 39 (3), 277-292.

Montes, M., Abánades, A., Martínez-Val, J., Valdés, M., 2009. Solar multiple optimization for a solar-only thermal power plant, using oil as heat transfer fluid in the parabolic trough collectors. Solar Energy 83 (12), $2165-2176$.

N.A Engineering, 2008. National academy of engineering. grand challenges for engineering.

URL www .engineeringchallenges .org

Palma del Río I, 2018.

URL https://www.nrel.gov/csp/solarpaces/project_detail. cfm/projectID $=18$

Rohani, S., Fluri, T., Dinter, F., Nitz, P., 2017. Modelling and simulation of parabolic trough plants based on real operating data. Solar Energy 158, 845 - 860 .

Sánchez, A. J., Gallego, A. J., Escaño, J. M., Camacho, E. F., 2018. Temperature homogenization of a solar trough field for performance improvement. Solar Energy. Elsevier. 165C, 1-9.

Sarbu, I., Sebarchievici, C., Jan. 2018. A comprehensive review of thermal energy storage. Sustainability 10 (1), 1-32.

Schenk, H., Dersch, J., Hirsch, T., Polklas, T., Sep. 2015. Transient simulation of the power block in a parabolic trough power plant. In: The 11th International Modelica Conference Versailles, France. Linköping University Electronic Press, Linköpings universitet, pp. 605-614.

SCHOTT Solar CSP GmbH, 2018. Schott ptr@70 receivers.

URL http://www. schott.com

Solaben 2, 2018.

URL https://www.nrel.gov/csp/solarpaces/project_detail. $\mathrm{cfm} /$ projectID $=231$

Solana Generating Station, 2018.

URL https://www.nrel.gov/csp/solarpaces/project_detail. $\mathrm{cfm} /$ projectID $=23$

Solar Millennium AG, 2018. The construction of the andasol power plants.

URL http://www.solarmillennium.de/english/archives/ technology/references-and-projects/andasol-spain/ andasol_artikel.html

System Advisor Model (SAM). NREL, 2018.

URL https://sam.nrel.gov/

Therminol VP1 HTF, 2018.

URL https://www.therminol.com/products/Therminol-VP1

Wittmann, M., Eck, M., Pitz-Paal, R., Müller-Steinhagen, H., 2011. Methodology for optimized operation strategies of solar thermal power plants with integrated heat storage. Solar Energy 85 (4), 653 - 659, solarPACES 2009. 